\title{
Enabling Indium channels for Mass Cytometry by using reinforced cyclam- based chelating polylysine
}

\author{
Laura Grenier, ${ }^{a}$ Maryline Beyler, ${ }^{*, a}$ Taunia Closson, ${ }^{b}$ Nick Zabinyakov, ${ }^{b}$ Alexandre Bouzekri, ${ }^{b}$ Yefeng Zhang, ${ }^{c}$ \\ Jothir Mayanantham Pichaandi, ${ }^{c}$ Mitchell A. Winnik, ${ }^{c}$ Peng Liu, ${ }^{*, b}$ Olga I. Ornatsky, ${ }^{b}$ Vladimir Baranov ${ }^{b}$ and \\ Raphaël Tripier*,á \\ a Univ Brest, UMR-CNRS 6521 CEMCA, 6 avenue Victor le Gorgeu, 29200 BREST, France \\ ${ }^{\mathrm{b}}$ Fluidigm Canada Inc., 1380 Rodick Street, Markham, Ontario L3R 4G5, Canada \\ 'Department of Chemistry, University of Toronto, 80 Saint George Street, Toronto, Ontario M5S 3H6, Canada
}

The synthesis of a polylysine polymer functionalized with the previously reported astonishingly inert $\left[\ln (\mathbf{c b} \text {-te2pa) }]^{+}\right.$chelate was performed. A biotin end group allowed the conjugation to biotinylated beads by the intermediary of a Fluorescein isothiocyanate / neutravidin receptor. High quality Imaging Mass Cytometry ${ }^{\mathrm{TM}}$ trials, based on ${ }^{115}$ In detection were performed to highlight the behavior of the material. Anti-CD20 antibody was labeled by the so obtained In(III) modified polylysine using the biotin/neutravidin interaction. Ramos (CD2O[+]) and HL-60 (CD20[-]) cell lines were co-stained with the In(III) modified bioconjugate by finding the best staining conditions. Both immunofluorescence IF-M and Mass Cytometry analyses confirmed the specific binding of anti-CD20 onto Ramos cells. CyTOF ${ }^{R}$ histograms constructed on the ${ }^{115}$ In detection allowed to define and to separate, with a good signal-to-noise ratio, two populations (Ramos and HL-60). The inertness of $\operatorname{In}(\mathrm{III})-\mathrm{MCP}-\mathrm{Nav}$ over a three-month storage period was proved by performing new functionality tests involving Jurkat cells (CD20[-]) as well as the possibility of multiplexing trials involving the ${ }^{115}$ In channel. The results assure a promising future use of the previously announced [In(cb-te2pa) $]^{+}$complex based polymers for mass cytometry.

Electronic Supplementary Information (ESI) available: [1H NMR of TFA-Lys-NCA, Poly(TFA-L-Lys)-Btn, Poly(L-Lys)-Btn and (PEGpoly(L-Lys)-Btn); GPC chromatogram of Poly(L-Lys)-Btn; NMR integration for PEG number evaluation; . Selected areas of blanks' and beads' ${ }^{115}$ In integral intensities on IMC images of indium beads; Average ${ }^{154} \mathrm{Sm}$ counts per cell for Jurkat $(\mathrm{CD} 45[+])$ and Ramos (CD45[+]) cells; Overlayed histograms of Jurkat and Ramos cells]

\section{Introduction}

Mass cytometry is a technology of single-cell analysis allowing high multiplexed assays. ${ }^{1}$ Exploring the heterogeneity of cells among one type of cell population and evaluating simultaneously various cellular biomarkers is becoming a fundamental aspect of cancer and immune $^{2}$ related disease research or drug development. ${ }^{3}$ The method is based on the use of antibodies tagged by metalisotopes. ${ }^{4}$ Its strength lies precisely on the high number of channels available thanks to the high spectral resolution offered by mass spectrometry; unlike the recurrent and well-known spectral overlaps of the fluorescent probes used in flow cytometry.

While a vast range of antibodies or specific biological markers can be easily provided to target a large number of proteins of interest in various cellular cultures, limitations in both multiplicity and sensitivity still exist because of the lack of available metal isotopes. Consequently, investigations are now focused on finding new stable isotopes applicable for mass cytometry to increase the number of channels, and thus, the number of analysable biomarkers. To be viable for mass cytometry, i.e. within the detection range of the instrument, metals should preferably belong to exogenous posttransition elements or to the rare-earth family. Lanthanides, with their 38 isotopes, are currently the most used labelling metals. They possess similar chemical properties enabling conjugation to antibodies through a unique protocol. ${ }^{4}$ However, they have the disadvantage to form oxides that interfere with the heavier lanthanides by generating a contamination in the +16 channel. $^{4}$

Among potential metal cations usable for mass cytometry, indium(III) appears like a reasonable choice. Natural indium is constituted of two isotopes, ${ }^{113}$ In and ${ }^{115} \mathrm{In}$, with $4.3 \%$ and $95.7 \%$ of respective isotopic abundance. Also, indium(III) is absent from biological media and does not form any interfering oxides. For all these reasons, this metal cation is already used in custom designed panels. ${ }^{55}$ However, ions of this molecular weight range suffer of a low ion transmission efficiency ${ }^{1}$ and need to be employed with chelate-containing polymers that multiply the number of metal units detected. Chelators commonly used to design metal chelating polymers (MCPs) are $\mathrm{H}_{5}$ dtpa (diethylenetriamine pentaacetic acid) and $\mathrm{H}_{4}$ dota $(1,4,7,10$-tetraazacyclododecane-1,4,7,10-tetraacetic acid) (Figure 1). However the high thermodynamic stability of their In(III) complexes does not prevent their dissociation. This is especially true with the linear ligand $\mathrm{H}_{5} \mathrm{dtpa}$. The main consequence of the poor kinetic inertness is the potential loss of metal during the immunostaining steps and the subsequent reductions of signal intensities. 
<smiles>O=C(O)CN(CCN(CC(=O)O)CC(=O)O)CC(=O)O</smiles><smiles>O=C(O)CN1CCN(CC(=O)O)CCN(CC(=O)O)CCN(CC(=O)O)CC1</smiles><smiles>O=C(O)c1cccc(CN2CCCN(CCN3CCCN(Cc4cccc(C(=O)O)n4)CC3)CC2)n1</smiles>

$\mathrm{H}_{2} \mathrm{cb}$-te2pa

Fig. 1 Chemical structures of the discussed ligands.

In a recent work, we described an extremely inert indium complex formed with a reinforced "cross-bridged" dipicolinate cyclam [In(cbte2pa)] $]^{+}$(Figure 1). This previous study led to a first proof of concept on Imaging Mass Cytometry (IMC ${ }^{\mathrm{TM}}$ ) with the use of polyamino polystyrene beads grafted with the bifunctional isothiocyanate analogue of $[\ln (\mathbf{c b}-t e 2 p a)]^{+}$. IMC images of good quality of the resulting beads were obtained due to the efficient detection of ${ }^{115} \operatorname{In}$. In this paper, we demonstrate that the In(III) chelate $[\ln (\mathbf{c b}-\mathrm{te} 2 \mathbf{p a})]^{+}$can be used for single-cell analysis by mass cytometry through the detection of ${ }^{115} \mathrm{In}$ and ${ }^{113} \mathrm{In}$. For that, [ In(cbte2pa)] $]^{+}$was grafted on a water soluble polymer and the corresponding MCP was subsequently tested for single-cell analysis by CyTOF, a specific mass cytometry technology where metalbearing cells are detected and quantified by Time-Of-Flight (TOF) mass spectrometry.

Various examples of metal chelating polymers have been described in the literature either for mass cytometry $^{6}$ or for medical diagnostic applications. ${ }^{7,8,9}$ In many of them, the polymer carried, a maleimide end group to enable the coupling onto antibodies after reduction of the S-S bond. ${ }^{6,10}$

In this new step of our investigation, we describe the synthesis of a polylysine functionalized by the previously reported indium chelate [In(cb-te2pa) $]^{+}$and a biotin (Btn) end group. The latter allows fast and efficient bioconjugation on beads or antibodies via the very strong and fast biotin-neutravidin non-covalent interactions. ${ }^{11,12}$ Neutravidin (NAv) has the advantage over avidin or streptavidin of having a neutral isoelectric point $(\mathrm{pl}=6.3$ ) and thus to be neutral at $\mathrm{pH}$ 6-7 and to lead to the lowest nonspecific binding. ${ }^{13} \mathrm{NAv}$ can also be labelled by fluorophore groups, such as fluorescein (FITC), to follow the bioconjugation by optical spectroscopy. The two-site "sandwich-like" biotin/neutravidin pairing is widely exploited for immunoassays, especially ELISA bioassays ${ }^{14,15,16}$ and appears as a linkage of choice for rapidly screening polymers' viability.

In a first intention, the indium polylysine-biotin was bioconjugated on biotinylated beads by the intermediary of a FITC-labeled NAv receptor. Imaging Mass Cytometry (IMC) experiments, focused on the ${ }^{115}$ In detection, proved the potential of the indium containing polymer for more sophisticated CyTOF experiments on live cells. The single cell analysis of HL-60 and Ramos cells based on the labelling of anti-CD20 antibodies with indium, as well as the demonstration of the stability of the In(III)-MCP-NAv conjugates are described here
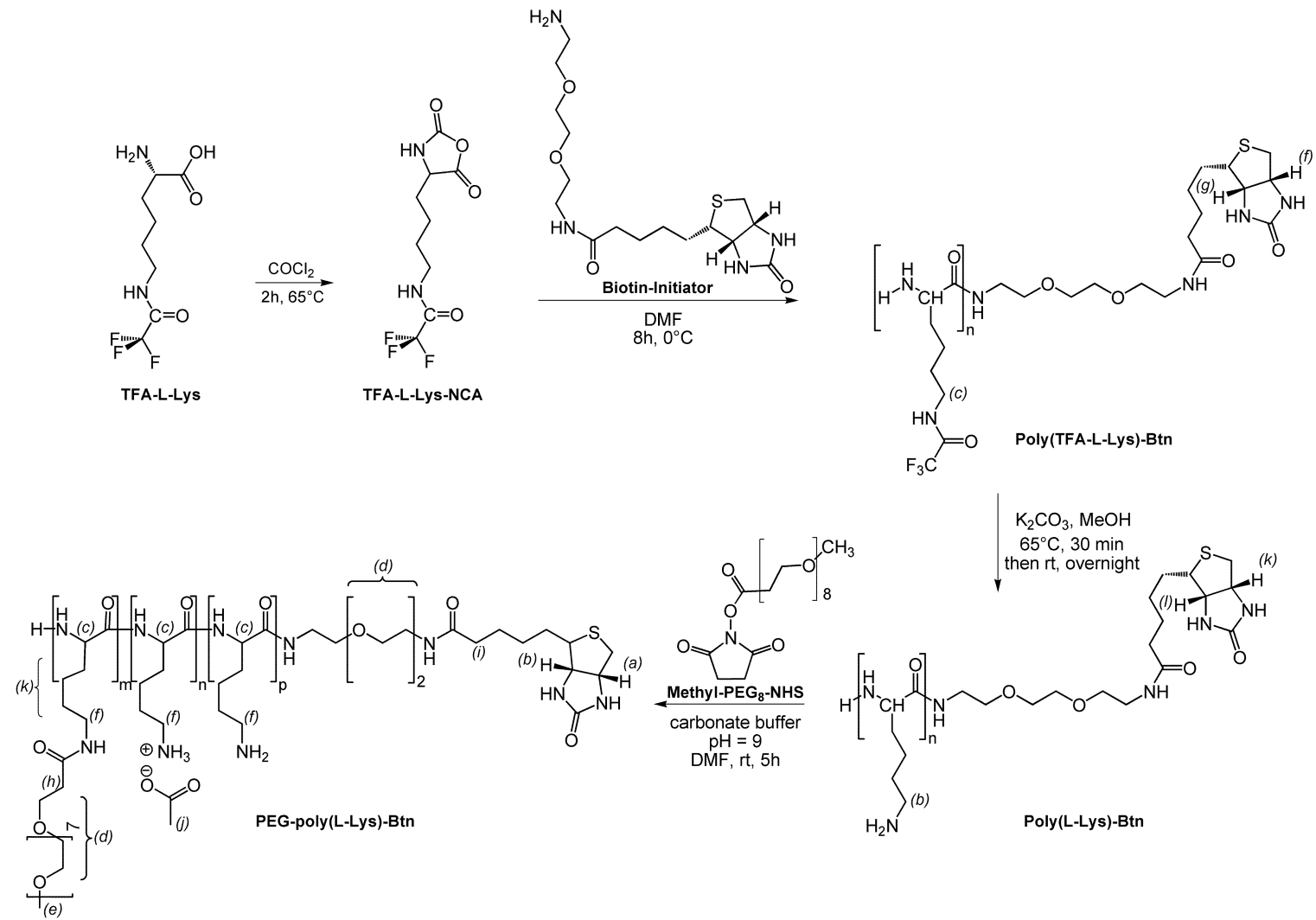

Fig. 2 Preparation of the modified polyamino poly-L-lysine polymer. 


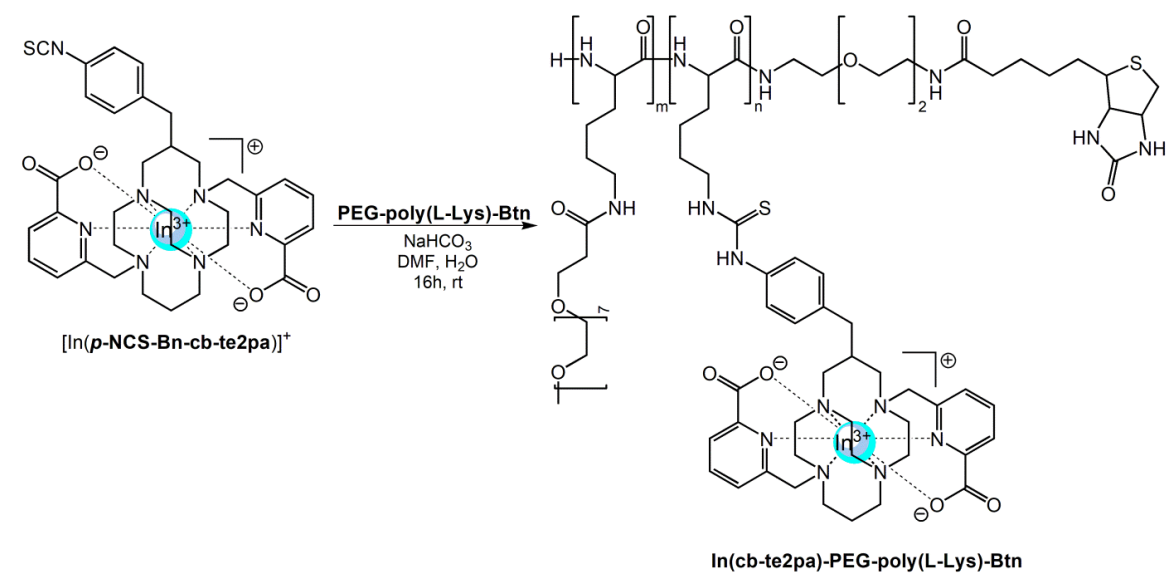

Figure 3. Synthesis of the indium containing polymer In(cb-te2pa)-PEG-poly(L-Lys)-Btn.

\section{Results and Discussion}

\section{Preparation of the indium polymer}

The synthesis of modified polyamino poly-L-lysine polymer described on Figure 2, started with the activation of TFA-L-lysine into its $N$-carboxyanhydride derivative (TFA-L-Ly-NCA) with phosgene. The protocol has been adapted from the synthesis of benzyl-L-glutamate-NCA. ${ }^{17}$ TFA-L-Ly-NCA was obtained in good yield and characterized by ${ }^{1} \mathrm{H}$ NMR (Figure S1 in Supporting Material). The biotin derivative with a primary amine was used as the initiator to trigger the ring opening polymerization of TFA-L-LyNCA. Following the polymerization, Poly(TFA-L-Lys)-Btn was recovered by precipitation from diethyl ether. ${ }^{18}$ We estimated the number average molecular weight $\left(M_{n}\right)$ of the polymer via end group analysis based on its ${ }^{1} \mathrm{H}$ NMR spectrum (Figure S2 in Supporting Material). Setting protons ( $f$ ) and $(g)$ of the biotin end group as references $(1 \mathrm{H})$ lead to an integration of $104 \mathrm{H}$ for the $\mathrm{CH}_{2}$ protons $(c)$, thereby a polymerization degree $\left(D P_{n}\right)$ of 52 was deduced.

Poly(TFA-L-Lys)-Btn was reacted with $\mathrm{K}_{2} \mathrm{CO}_{3}$ in $\mathrm{MeOH}$ to recover the free primary amine functions. No degradation of the polymer during this deprotection step occurred since the $D_{n}$ was unchanged (see Figure S3 in Supporting Material). Knowing the degree of polymerization, a molecular weight of $M_{\mathrm{n}} \approx 5400 \mathrm{~g} / \mathrm{mol}$ could be estimated. This value was checked by analysis on size exclusion chromatography (SEC). To avoid the interactions of amine polymer bearing cationic pendant groups with the stationary phase of the SEC columns, the samples were treated prior to analysis with excess of succinic anhydride in carbonate buffer $(0.1 \mathrm{M}, \mathrm{pH}=9.4)$ to convert all the amino groups into carboxylic acid group. The SEC chromatogram of the succinic modified-polymer (Figure S4) shows a peak with a retention volume of $15.2 \mathrm{~mL}$ which corresponds to a molecular weight of $M_{\mathrm{n}}^{\mathrm{SEC}}=13400 \mathrm{~g} / \mathrm{mol}$ (standards calibrated by PMAA). Considering the estimated $M_{\mathrm{n}}$ this result leads to a polydispersity index $(\boxplus)$ of 1.04 .

In order to ensure the hydrosolubility of the poly-L-lysine polymer, half of the primary amine functions were expected to react with the activated $\mathrm{N}$-hydrosuccinimic ester of methyl-PEG ${ }_{8}-\mathrm{NHS}$ (25 eq.). The
${ }^{1} \mathrm{H}$ NMR spectrum of the isolated PEGylated poly-L-lysine (PEGpoly(L-Lys)-Btn) is displayed in Figure S5. The integrations of some characteristic signals allowed us to estimate the composition of the polymer (see Table S1 in Supporting Material). These calculations showed that on average only 17 amine groups per chain were PEGylated and consequently 35 are still available for the grafting of the $\left[\operatorname{In}(\mathbf{c b}-\text { te2pa) }]^{+}\right.$chelate. In a previous report about IMC by ${ }^{115} \mathrm{In}$ detection, the phenyl isothiocyanate bifunctional analogue of $[\ln (\mathbf{c b}-\mathrm{te} 2 \mathrm{pa})]^{+}$was directly grafted onto polyamino beads. ${ }^{19}$ In this work, the covalent attachment of the indium complex [ In( $p$-NCS$\mathrm{CH}_{2} \mathrm{Ph}$-cb-te2pa)] $]^{+}$on the polylysine polymer PEG-poly(L-Lys)-Btn was also assured through the formation of very strong thiourea bonds (Figure 3).

The ${ }^{1} \mathrm{H}$ NMR spectrum of the indium chelate containing polymer In(cb-te2pa)-PEG-poly(L-Lys)-Btn was recorded and is given on Figure 4. The apparition of aromatic signals from 7.3 to $6 \mathrm{ppm}$, belonging to the picolinate and benzyl groups of $[\ln (\mathbf{c b}-\mathrm{te} 2 \mathrm{pa})]^{+}$ strongly suggests that the coupling of the complex on the polymer occurred. However, the signals of the biotin end-group cannot be clearly identified, which makes it difficult to calculate the number of grafted indium complexes by NMR.

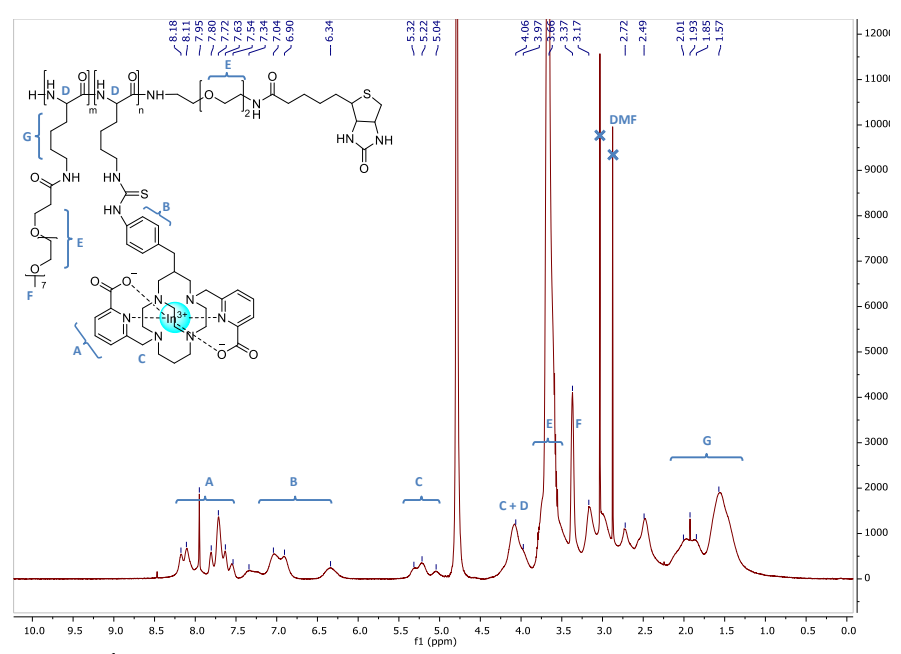

Fig. $4{ }^{1} \mathrm{H}$ NMR (500 MHz, $\mathrm{D}_{2} \mathrm{O}, 298 \mathrm{~K}$ ) of the indium chelate containing polymer In(cb-te2pa)-PEG-poly(L-Lys)-Btn. 
Therefore, in an attempt to evaluate the number of chelates attached to the PEGylated polylysine, indium content was measured by ICP-MS. An experimental indium content of $0.101 \mathrm{ppm}$ was measured. In theory, if the 35 available amino positions of PEGpoly(L-Lys)-Btn reacted with the indium complexes [In(p-NCS$\mathrm{CH}_{2} \mathrm{Ph}$-cb-te2pa) $]^{+}$, the molecular weight of the resulting indium complexes containing polymer In(cb-te2pa)-PEG-poly(L-Lys)-Btn is evaluated at $42000 \mathrm{~g} / \mathrm{mol}$. This corresponds to a theoretical indium content of $0.957 \mathrm{ppm}$. The comparison with the experimental value indicates a $10 \%$ grafting rate, which means In(cb-te2pa)-PEGpoly(L-Lys)-Btn is carrying 3 to 4 indium chelates per polymer.

\section{Bioconjugation and Imaging Mass Cytometry}

As explained earlier, biotinylated polymers were chosen to demonstrate the conjugation capability of our Indium-polymers (Figure 5). The highly modular capacity of this strategy is a great advantage. Also, to verify the efficiency of the bioconjugation by ImmunoFluorescence Microscopy (IF-M), neutravidin was firstly modified with a fluorescent dye, Fluorescein isothiocyanate (FITC).

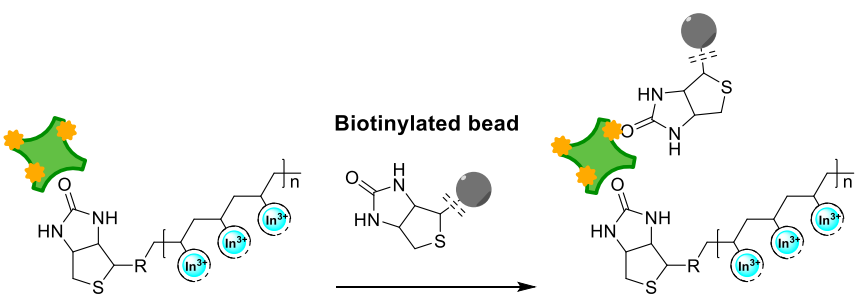

Indium FITC-NAv Conjugate

Fig. 5 Principle of the biotinylated bead strategy.

Neutravidin was reacted with FITC in carbonate buffer. The fluorescent dye was attached to NAv through the formation of a thiourea linker. Prior to bioconjugation, the concentration of NAv and the FITC/NAv molar ratio of the solution were quantified. A concentration of $2.6 \mathrm{mg} / \mathrm{mL}$ NAv with $3.3 \mathrm{FITC}$ per NAv was determined by UV/Vis. Knowing the FITC content is important to retrieve later the concentration of the In(III)-MCP-NAv conjugate solution. Indeed, the absorption of the picolinate moieties at 280 $\mathrm{nm}$ prevents any protein quantification by the usual method. Instead, the absorbance of FITC at $495 \mathrm{~nm}$ leads to a known concentration of NAv and therefore of the conjugate.
The conjugation of the polymer and NAv was performed by adding a slightly excess (1.3 eq.) of In(cb-te2pa)-PEG-poly(L-Lys)-Btn to the solution of FITC/NAv.

After purification by filtration with spin-filter, the bioconjugate (obtained with a solution of polymer at $2 \mathrm{mg} / \mathrm{mL}$ ) was characterized by Fast Protein Liquid Chromatography (FPLC) equipped with size exclusion column (SEC) and compared to FITC/NAv. The superposition of both chromatograms is presented on Figure 6 . The shorter retention time of the indium conjugate compared to FITC/NAv attests the successful conjugation of the biotinylated indium polylysine onto the modified NAv with NAv having probably most of it binding sites free.

Attempts to increase the number of conjugated indium polylysines onto the modified neutravidin led to solubility issues suggesting that the presence of too many polymer chains would decrease the water solubility of the conjugates. Among possible explanations for this phenomenon are the hydrophobicity of the resulting conjugate or unknown interferences between the indium polymer and the FITC-NAv.

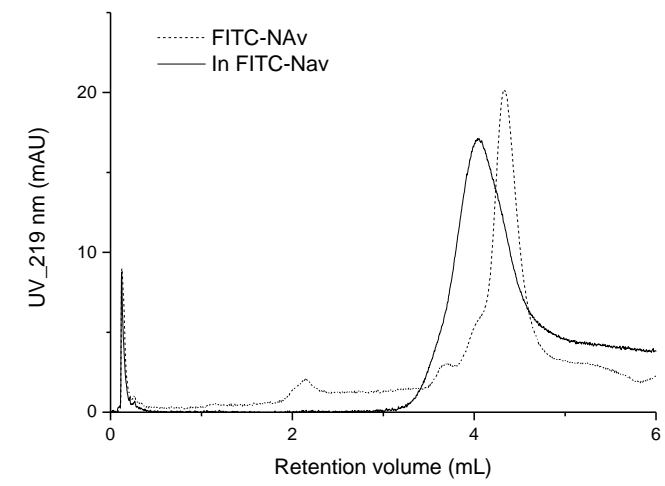

Fig. 6 FPLC chromatograms of FITC/NAv before (....) and after (_) bioconjugation with the indium containing polylysine.

Therefore, functionality tests on the biotinylated beads were performed considering each Nav has more than one complexation sites available. $3 \mu \mathrm{g}$ of polymer were mixed with biotinylated beads and the grafting of the indium-polylysine conjugates was firstly evidenced by Immunofluorescence IF-M using the FITC channel. 
Table 1. Reaction conditions and ICP-MS results for the incubation of the indium FITC-NAv conjugate onto the biotinylated beads.

\begin{tabular}{|c|c|c|c|c|}
\hline Assay & $\begin{array}{c}\text { Amount of indium FITC-NAv } \\
\text { Conjugate }(\mu \mathrm{g})\end{array}$ & $\begin{array}{l}\text { Measured [In] by ICP- } \\
\text { MS }\left(\mathrm{mg}_{\mid \mathrm{ln}} \cdot \mu \mathrm{L}^{-1}\right)\end{array}$ & $\begin{array}{l}\text { Calculated number of } \\
\text { indium atom/ beads }^{a}\end{array}$ & Conjugation rate \\
\hline 1 & 3 & $2.41 \times 10^{-7}$ & 262 million & $4 \%$ \\
\hline 2 & 5 & $3.54 \times 10^{-7}$ & 385 million & $6 \%$ \\
\hline
\end{tabular}

${ }^{a}$ Calculated with: $\boldsymbol{X}_{I n}=\frac{N_{A}[I n] \times 10^{-3}}{4820 \times M W_{I n}}$ with $\mathrm{N}_{\mathrm{A}}=$ Avogadro number $\left(6.22 \times 10^{23} \mathrm{~mol}^{-1}\right),[\mathrm{In}]=$ indium content measured by ICP-MS in mg. $\mu \mathrm{L}^{-1}$, concentration of the beads solution $=4820$ beads. $\mu \mathrm{L}^{-1}$ (according to manufacturer's information [https://www.bangslabs.com/sites/default/files/imce/docs/PDS\%20724\%20Web.pdf])

A blank sample was realized with beads from commercial solution that have not been in contact with any FITC-NAv. IF-M images displayed on Figure 7 indicate a positive signal from FITC fluorescence at low exposure time. The observed FITC fluorescence also indicates a homogeneous staining of the indium FITC-NAv onto the beads. IF-M images are promising regarding the presence of the indium FITC-NAv conjugate onto the beads. To go deeper in the characterization of the beads the quantification of the indium content was determined by ICP-MS after acidic digestion.

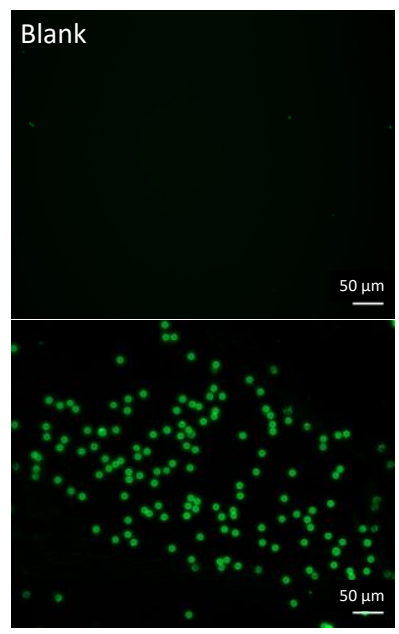

Fig. 7 IF-M images of biotinylated beads (top) and biotinylated beads conjugated with indium polylysine FITC-NAv (bottom).

A concentration of $2.41 \times 10^{-7} \mathrm{mg}_{\mathrm{In}} \cdot \mathrm{\mu L}^{-1}$ was measured (Assay 1,
Table 1). The initial concentrations of biotin and beads were $[\mathrm{Btn}]=$ $5.9 \cdot 10^{-9} \mathrm{~mol} \cdot \mathrm{mg}^{-1}$ and $[$ Beads $]=1.926 \cdot 10^{6} \mathrm{mg}^{-1}$ respectively. Applying these data into the formula biotins/bead $=[\mathrm{Btn}] \boldsymbol{N}_{A} /[\mathrm{Beads}]$ led to an estimated value of biotin molecules per bead of 1.8 billion. Considering also that there are 3 to 4 indium chelates per polylysine and $\sim 1$ polylysine per FITC/NAv, it is reasonable to assume that if $100 \%$ of biotin would be conjugated with one indium FITC-NAv conjugate, around 6 billion of indium atoms per bead should be introduced. This reflects a very low conjugation rate of $4 \%$ onto the beads. To improve the grafting rate a higher amount of polymer $(5 \mu \mathrm{g})$ was used (Assay 2, Table 1). The conjugation rate was only slightly increased. This could be explained by the biotin distribution onto the beads and/or non-innocent interferences of the indium polymer with the remaining available active sites of the neutravidin. These interferences from the previous bioconjugation step could prevent an efficient binding with the biotinylated beads.

Indium beads were firstly studied by Imaging Mass Cytometry. IMC emanates from mass cytometry and is generally used for the study of histological sections. The detection is based on plumes of particles generated by laser ablation. Indium beads were deposited on IMC slides and could clearly be observed on IMC images (Figure 8(a)) indicating a good detection of ${ }^{115}$ In despite the low ion transmission of this ion in mass cytometry. Theoretically, ${ }^{113}$ In can also be detected; however, it has an isotopic abundance of only $4 \%$ and was therefore not investigated in this purpose neither for the rest of the functionality tests on cells.

For each bead studied, an area of $14 \mu \mathrm{m}$ by $14 \mu \mathrm{m}$ was selected, in other words an area of 196 pixels. Each pixel has an associated

Table 2. ${ }^{115}$ In Integral intensities from various beads from Month 0 and Month 1.

\begin{tabular}{|c|c|c|c|c|c|}
\hline Month & Beads & $\begin{array}{l}{ }^{115} \text { In Integral } \\
\text { Intensity }\end{array}$ & Average Integral & Integral CV (\%) & $\begin{array}{c}\text { Normalized Average }{ }^{115} \text { In Integral (Norm. } \\
\text { Factor }=1.54 \text { ) }\end{array}$ \\
\hline \multirow{4}{*}{0} & 1 & 14537.27 & \multirow{4}{*}{18695.3} & \multirow{4}{*}{$16.5 \%$} & \multirow{4}{*}{18695.3} \\
\hline & 2 & 21169.25 & & & \\
\hline & 3 & 20897.86 & & & \\
\hline & 4 & 18176.89 & & & \\
\hline \multirow{4}{*}{1} & 1 & 10963.22 & \multirow{4}{*}{12383.4} & \multirow{4}{*}{$7.9 \%$} & \multirow{4}{*}{19070.37} \\
\hline & 2 & 13181.83 & & & \\
\hline & 3 & 12785.81 & & & \\
\hline & 4 & 12602.57 & & & \\
\hline
\end{tabular}


metal intensity (count). The integral for the bead area is the sum of all the metal counts for all the pixels selected and CV\% is calculated by the standard deviation of all integrals divided by the average integral. Detailed ${ }^{115}$ In intensities are displayed in Table 2 (see Month 0) and the highlighted areas of selected beads are shown in Figure $\mathrm{S6}$.

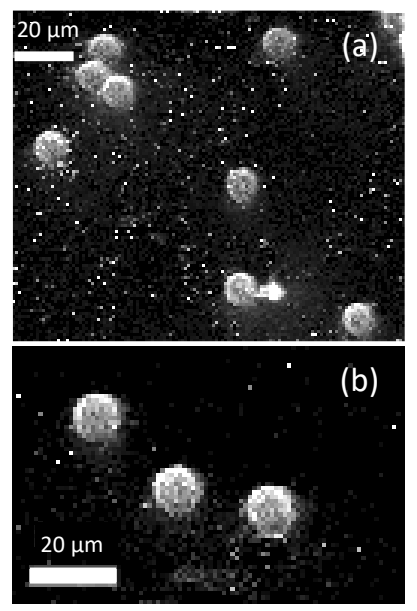

Fig. $8 \mathrm{IMC}^{\mathrm{TM}}$ images microbeads with ${ }^{115}$ In channel of biotinylated beads conjugated with indium polylysine FITC-NAv (MCD ${ }^{T M}$ Viewer with threshold min set to 1 and threshold max set to 400) recorded at (a) Month 0 and (b) Month 1. All scale bars were re-drawn for clarity.

${ }^{115}$ In integral intensities are very satisfying with an average of 18695.3 counts. These results underline the ability of this macrocyclic family to chelate indium for mass cytometry applications. Next, to test the stability of the indium polymer over time, IMC images were acquired using grafted beads aged for 1 month in PBS at $4^{\circ} \mathrm{C}$ (Figure $8($ b)).

${ }^{115}$ In intensities were determined according to the same procedure as described above. However, in order to compare results over time, values had to be normalized due to daily instrument variations. $\mathrm{EQ}^{\mathrm{TM}}$ Four Element Calibration beads containing ${ }^{140 / 142} \mathrm{Ce},{ }^{151} /{ }^{153} \mathrm{Eu},{ }^{165} \mathrm{Ho}$, and ${ }^{175 / 176} \mathrm{Lu}$ were deposited on the same
IMC slide. A normalization factor was calculated using ${ }^{140} \mathrm{Ce}$ due to its closest mass value, and by comparing its average integral intensity during both experiments.

After 1 month, ${ }^{115}$ In counts were comparable (Table 2) and demonstrate the inertness and stability of the indium chelate based on a reinforced cross-bridged cyclam derivative, and of the whole bioconjugated beads. In light of these very encouraging results, functionality tests on cells were performed to evaluate the behavior of this new indium polymer in biological media and staining conditions.

\section{Functionality tests on cells}

To report the efficiency of a metal-tagged staining agent, immunostainings were performed by targeting a precise antigen on two known cell lines. More precisely, a first cell line expressing the studied antigen and therefore inducing a positive signal was chosen and compared to a second one showing no expression (Figure 9). The aim was to determine the signal-to-noise ratio of the new indium staining agent. The positive signal refers to the efficiency of indium polylysine polymer as a reporting agent for the studied antigen; whereas the noise measures the signal from non-specific staining either due to inadequate staining conditions or from modifications brought upon the antibody during the conjugation procedure.

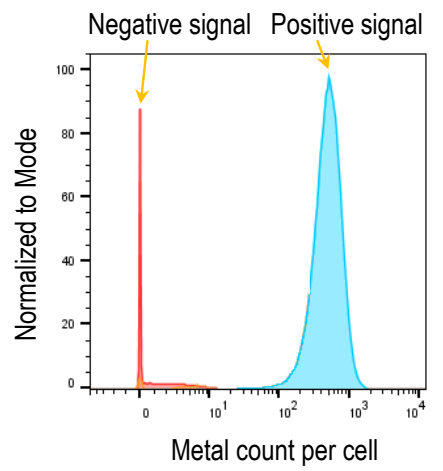

Fig. 9 Signal-to-noise ratio of the indium staining agent.

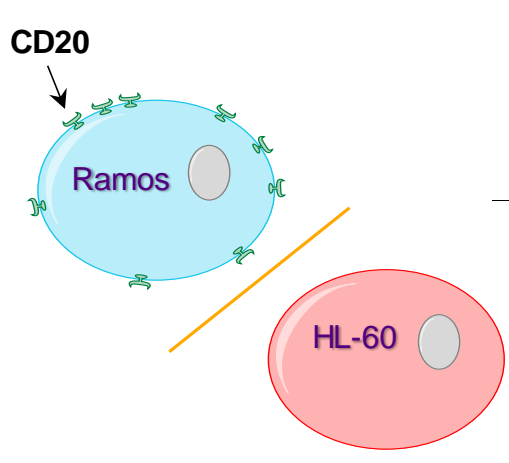

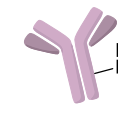

Biotinylated anti-CD20 Ab

2.

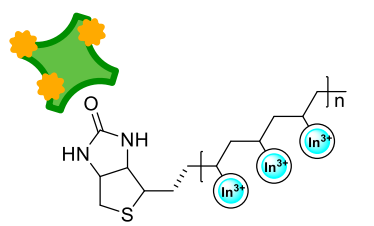

[In(cb-te2pa)FITC-NAv] conjugate

Various staining concentrations $\left(\sim 10^{-3} \mathrm{mg} \cdot \mathrm{mL}^{-1}\right)$
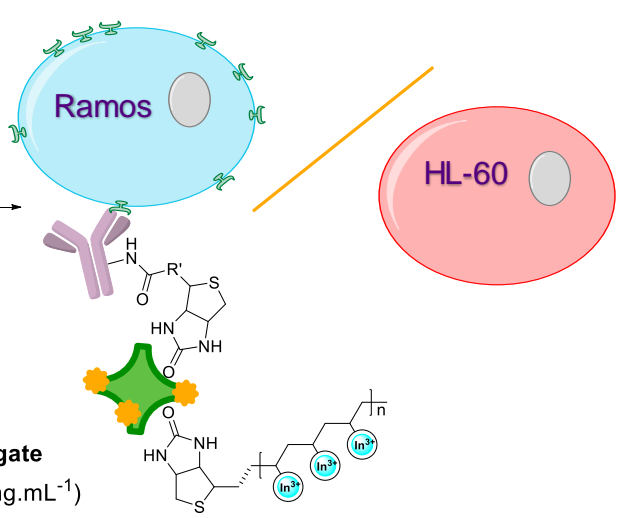

Fig. 10 Experiment design to evaluate signal to noise ratio of the indium-staining agent. 
In this work, Ramos cells, which express CD20, were used as the positive control. HL-60 cells, which do not express CD20 served as the negative control. The bioconjugation of the indium polymer In(cb-te2pa)-PEG-poly(L-Lys)-Btn onto cells was based on the biotin-neutravidin interaction. That is why, in a first step, the cell lines were stained with the primary antibody anti-CD20 that recognizes the antigen $C D 20$ if this one is expressed. Since antiCD20 was functionalized by biotin, it allowed non-covalent secondary binding of the indium-polylysine-FITC/NAv conjugates (Figure 10).

Standard staining procedure required the use of $100 \mu \mathrm{L}$ of titers prepared in $0.5 \%$ BSA - PBS for $30 \mathrm{~min}$ at room temperature for $2 \times$ $10^{6}$ cells. $^{2,20,21}$ Due to a large amount of unspecific staining generating non-negligible background on the negative HL-60 population, a different procedure was adapted. Staining was done in PBS on ice for 1h; BSA was removed to prevent its carrier-effect and possible interaction with indium, and therefore non-specific staining. Once the cells were stained with primary antibody and indium FITC-NAv conjugate, a sample was used for controlling the presence of fluorescein under IF-M. Cells were counterstained with DAPI for nuclei identification. Images displayed in Figure 11 show autofluorescence of the studied cells which hinders the interpretation. ${ }^{22,23}$ In order to improve interpretation, a negative control of the fluorescein was performed by adding cell samples from each cell lines that were not incubated with the indium FITCNAv conjugate.

Positive signals, as indicated by brighter dots, were visible on FITC channel for the positive cell line at $3 \mu \mathrm{g} \cdot \mathrm{mL}^{-1}$ despite autofluorescence of the cells. This suggests that indium FITC-NAv conjugates were successfully labeling CD20 by the indium-labelled conjugate.

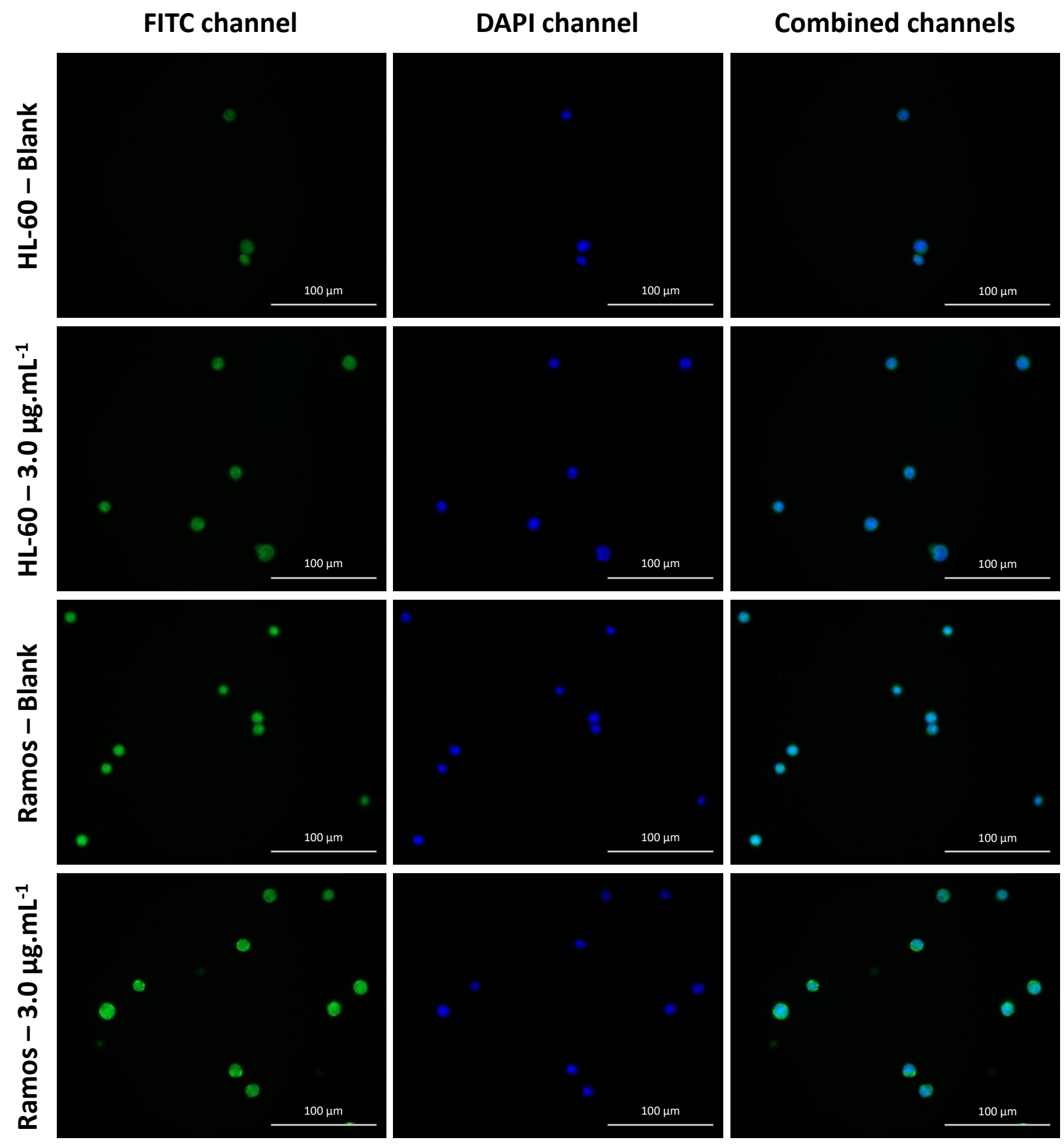

Fig. 11 IF-M images of Ramos (CD20[+]) and HL-60 (CD20[-]) cells stained without (blank) and with indium FITC-NAv conjugate at 3.0 $\mu \mathrm{g} \cdot \mathrm{mL}^{-1}$. Images were taken with $7 \mathrm{~s}$ of exposure time on the FITC channel, using Superfrost ${ }^{+}$slides. 
In order to confirm this observation and quantify indium content more accurately, stained cells were analyzed by СуTOF experiments. Cells were detected by the Helios ${ }^{\mathrm{TM}}$ mass cytometer through iridium staining of DNA. For each cell detected, indium counts were retrieved. Once data were collected, files were automatically processed by normalizing metal counts via the EQ Four Element Calibration bead counts. Beads and dead cells were removed from analyzed data via proper gatings in order to focus only on live cells. Indium-115 counts per cell were retrieved for each titer and resulting histograms are displayed on Figure 12. staining must be avoided to prevent false positive signals once using indium in antibody panels on mass cytometry.

All the different concentrations tested show very few ${ }^{115}$ In detections in the HL-60 cells. The comparison of $\mathrm{CD} 2 \mathrm{O}[+]$ and CD20[-] expressions lead to an average signal-to-noise ratio of 128 . This supposes a very few unspecific staining of the indium FITC-NAv conjugate. In addition, it is worth noting that metal ions such as indium suffer of low ion transmission compared to other metals or lanthanides commonly used in ICP-MS. Therefore, the intensity
Staining at $0.3 \mu \mathrm{g} \cdot \mathrm{mL}^{-1}$

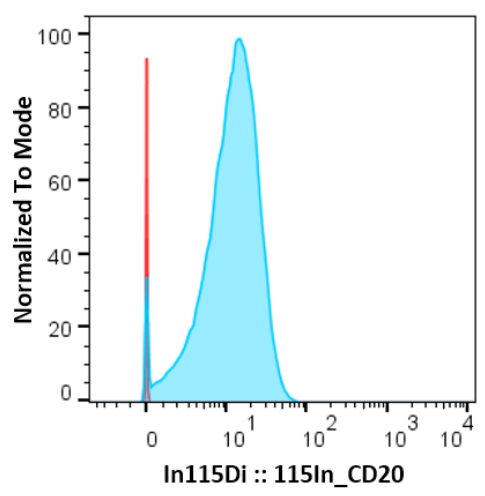

Staining at $1.0 \mu \mathrm{g} \cdot \mathrm{mL}^{-1}$

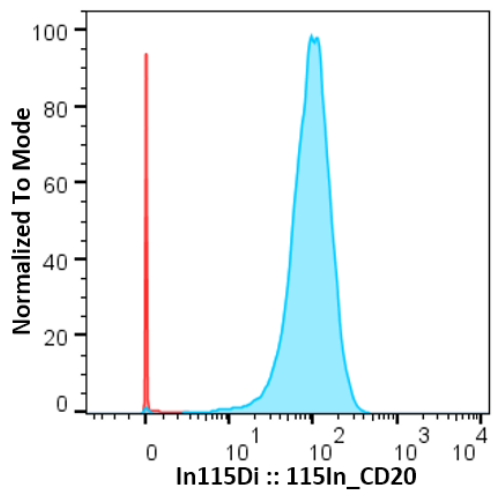

Staining at $3.0 \mu \mathrm{g} \cdot \mathrm{mL}^{-1}$

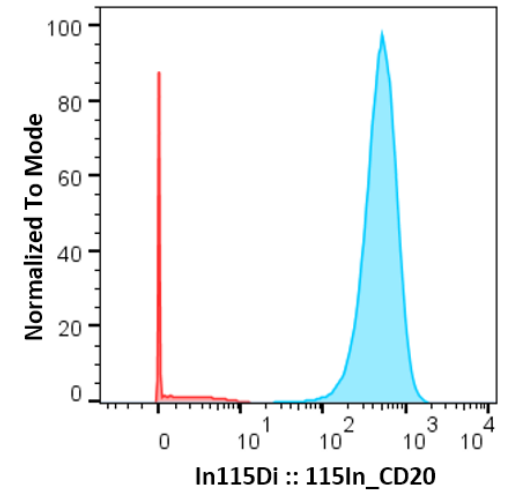

Fig. 12 Overlayed histograms of HL-60 (CD20[-]) (red) and Ramos (CD20[+]) (blue) cells on ${ }^{115}$ In channel, detected by indium staining agent at various titers.

Detailed indium counts are summarized in Table 3.

Table 3. Average ${ }^{115}$ In counts per cell for HL-60 (CD20[-]) and Ramos (CD20[+]) cells.

\begin{tabular}{ccc}
\cline { 2 - 3 } & \multicolumn{2}{c}{ Mean ${ }^{115}$ In count per cell } \\
\cline { 2 - 3 } & HL-60 (CD20[-]) & $\begin{array}{c}\text { Ramos } \\
\text { (CD20[+]) }\end{array}$ \\
\hline $\mathbf{0 . 3} \boldsymbol{\mu g} \cdot \mathrm{mL}^{-1}$ & 0.16 & 14 \\
$\mathbf{1 . 0} \boldsymbol{\mu g} \cdot \mathrm{mL}^{-1}$ & 0.71 & 102 \\
$\mathbf{3 . 0} \boldsymbol{\mu g} \cdot \mathrm{mL}^{-1}$ & 3.36 & 516 \\
\hline
\end{tabular}

Here, we mainly focus on signal-to-noise ratio rather than $\mathrm{CD} 20$ expression itself. By overlaying $\mathrm{HL}-60$ and Ramos cell populations, one can determine from background if the antibody modified by the indium conjugate is inducing non-specific staining. Non-specific measured for ${ }^{115}$ In can be considered as very encouraging for the conception of metal labeling kits using indium isotopes.

In order to go further and illustrate the previous experiments, cells were deposited on slides and run through IMC. As a result, images of indium and therefore CD20 could be represented on cells in a way comparable to IF-M but without the autofluorescence issue (Figure 13). These images clearly show a bright detection of ${ }^{115}$ In in Ramos cells proving the specific labeling with the indium polylysine polymer. Some green spots corresponding to indium can also be observed on the HL-60 cells. However, they are only located on dead cells. To prove the non-specific uptake of indium polymer in HL-60 cells mainly occurs in dead cells, the indium counts from previous CyTOF experiments were retrieved by gating dead cell population (Figure 14). 
Staining at $0.3 \mu \mathrm{g} \cdot \mathrm{mL}^{-1}$ ${ }^{115}$ In / DNA / Dead
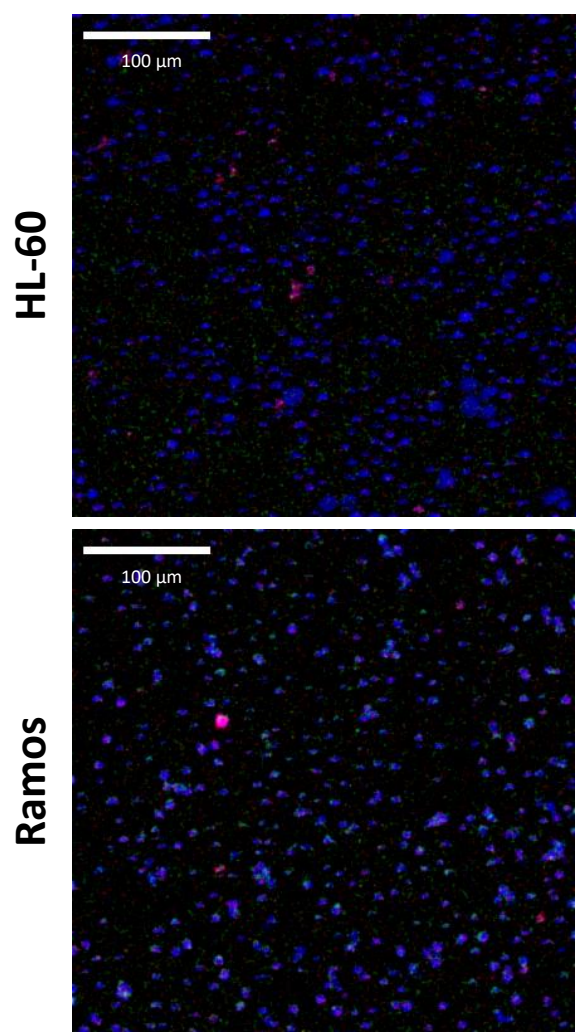

Staining at $1.0 \mu \mathrm{g} \cdot \mathrm{mL}^{-1}$

115 In / DNA / Dead
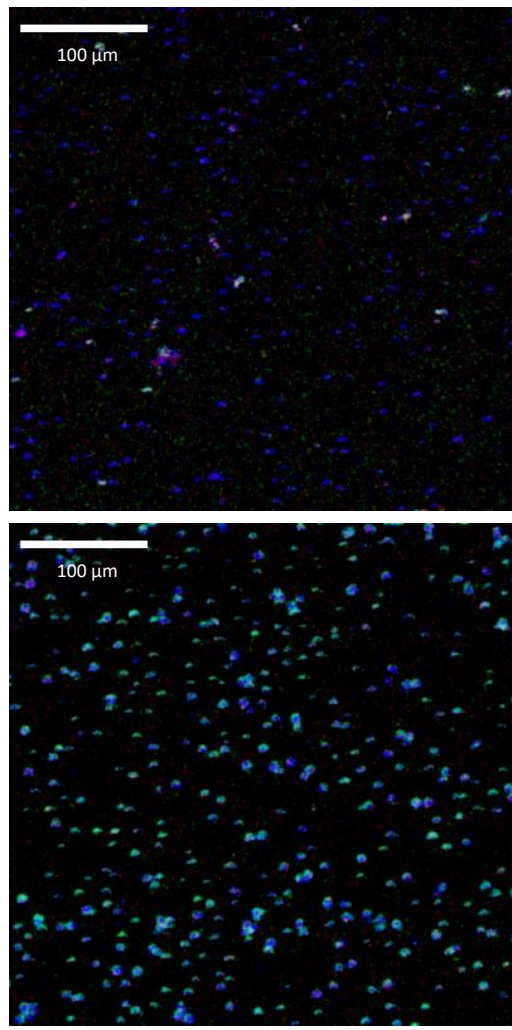

Staining at $3.0 \mu \mathrm{g} \cdot \mathrm{mL}^{-1}$

115 In / DNA / Dead
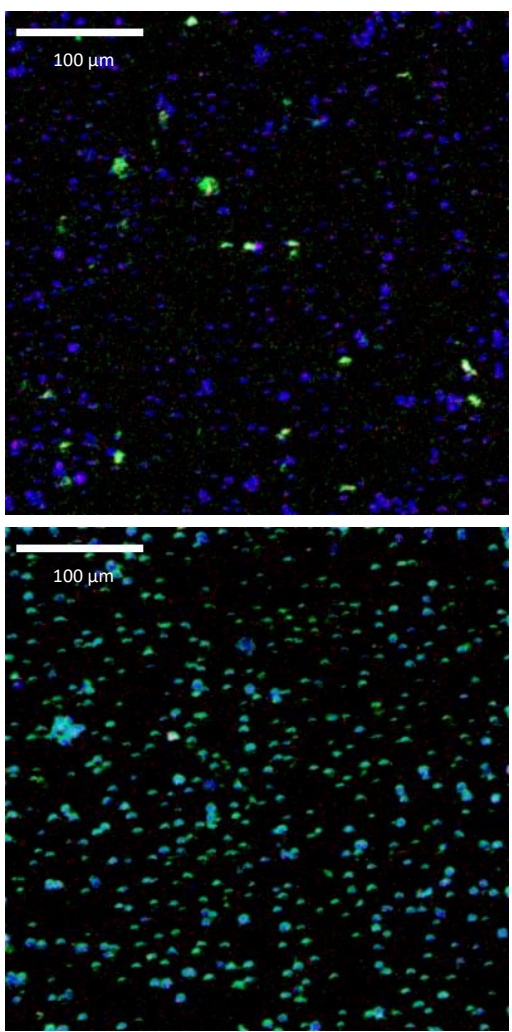

Figure 13. IMC images of HL-60 (CD20[-], top) and Ramos (CD2O[+], bottom) cells stained with indium FITC-NAv conjugate at various titers.

is internalized in cells inducing the observed indium background on IMC. By gating live cells only, data analysis of CyTOF experiments presents the advantage to discard indium count from this unspecific

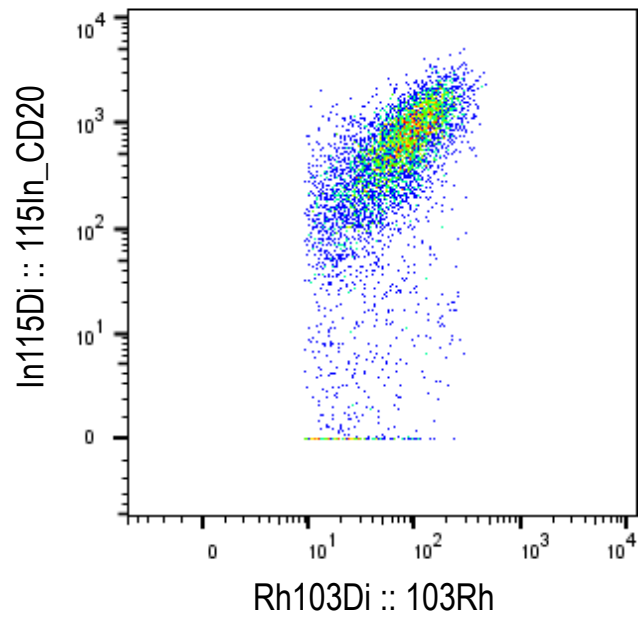

Figure 14. ${ }^{115}$ In count for dead cell population on HL-60 (CD20[-]) at $3 \mu \mathrm{g} / \mathrm{mL}$. 
staining and analyze only relevant indium staining. However, IMC by Hyperion ${ }^{\mathrm{TM}}$ imaging system is mainly used to study tissues and not cell populations.

\section{Long-term stability}

As already mentioned, a kinetically inert metal complex is vital to prevent false-negatives on CyTOF experiments. This particular property was therefore study for the In(III)-MCP-NAv conjugate on an long-term functionality assay. In this assay, NAv was no longer modified with FITC. The In(III)-MCP-NAv conjugate was synthesized anew and the quantification of the In(III)-MCP-NAv was, this time, performed by Bradford assay. The Bradford assay is a colorimetric titration of protein, read at $595 \mathrm{~nm}$, using the Coomassie Blue. The dye shifts from red to blue, when binding to basic amino acids contained in the protein. A calibration curve, obtained with BSA standards from 0 to $2000 \mu \mathrm{g} \cdot \mathrm{mL}^{-1}$, allowed to retrieve the protein concentration of the desired sample.

To see if the high signal/noise ration can be extrapolated to other cell lines, new experiments were carried out by replacing HL-60 cells with Jurkat cells. Noteworthy, in the experiments with Jurkat cells, Fc block agent was used to reduce non-specific binding due to Fc receptors. In addition, Ramos and Jurkat cell lines were co- stained with anti CD45 labelled with ${ }^{154} \mathrm{Sm}$ (Maxpar ${ }^{\circledR}$ metal labeling kits). In fact, both Ramos and Jurkat cell lines have a high level expression of CD45. The assumption was to compare the intersample variability between two independent functional assays using CD45 as an internal control for standardization. The CD45 mean intensities can be used to determine a normalization factor that can be used to compare the mean intensity values of $\mathrm{CD} 20$ and to minimize the difference of signal range.

${ }^{115}$ Indium and ${ }^{154} \mathrm{Sm}$ counts were collected for each titer. The histograms are plotted on Figure 15, exact counts for each isotope are detailed in Table 4 and Table S2 for ${ }^{115}$ In and ${ }^{154} \mathrm{Sm}$ respectively.

Table 4. Average ${ }^{115}$ In counts per cell for Jurkat (CD20[-], CD45[+]) and Ramos (CD20[+], CD45[+]) cells at month 0 and month 3.

\begin{tabular}{ccccc}
\cline { 2 - 5 } & \multicolumn{2}{c}{$\begin{array}{c}\text { Mean }{ }^{\mathbf{1 1 5}} \text { In count/cell } \\
\text { (month 0) }\end{array}$} & \multicolumn{2}{c}{$\begin{array}{c}\text { Mean }{ }^{\mathbf{1 1 5}} \text { In count/cell } \\
\text { (month 3) }\end{array}$} \\
\cline { 2 - 5 } & $\begin{array}{c}\text { Jurkat } \\
(\mathrm{CD} 20[-])\end{array}$ & $\begin{array}{c}\text { Ramos } \\
(\mathrm{CD} 20[+])\end{array}$ & $\begin{array}{c}\text { Jurkat } \\
(\mathrm{CD} 20[-])\end{array}$ & $\begin{array}{c}\text { Ramos } \\
(\mathrm{CD} 20[+])\end{array}$ \\
\hline $\mathbf{0 . 2 5} \boldsymbol{\mu \mathrm { g } / \mathbf { m L }}$ & 1.01 & 8.45 & 0.83 & 48.74 \\
$\mathbf{0 . 5} \boldsymbol{\mu g} / \mathbf{m L}$ & 4.69 & 36.5 & 2.82 & 132.74 \\
$\mathbf{1 . 0} \mathbf{\mu g} / \mathbf{m L}$ & 11.8 & 79.6 & 13.30 & 422.50 \\
\hline
\end{tabular}


The histograms indicate that CD45 signal is consistent across these cells so that normalization to CD45 mean signal can be performed. cells. This can be explained by the difference in quantification methods used to prepare the conjugate solution for staining titers.

\section{${ }^{115}$ In channel (CD20)}
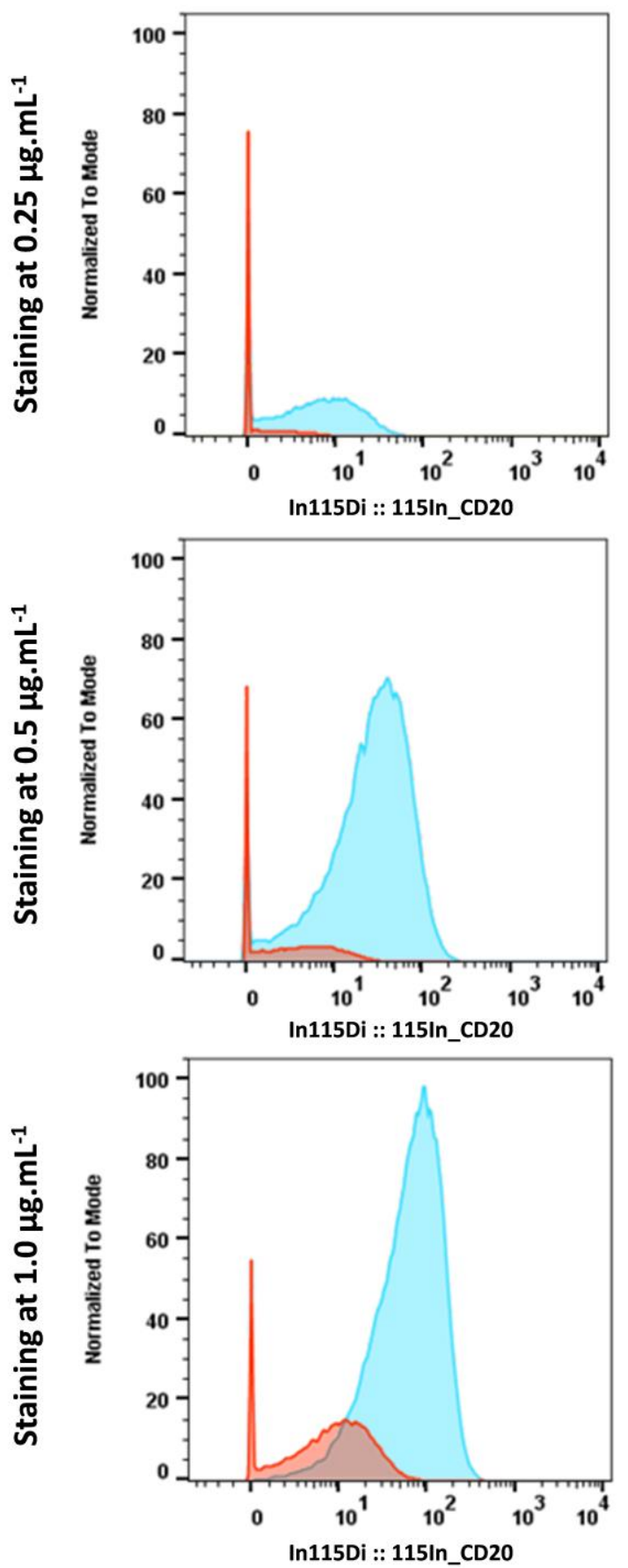

${ }^{154}$ Sm channel (CD45)
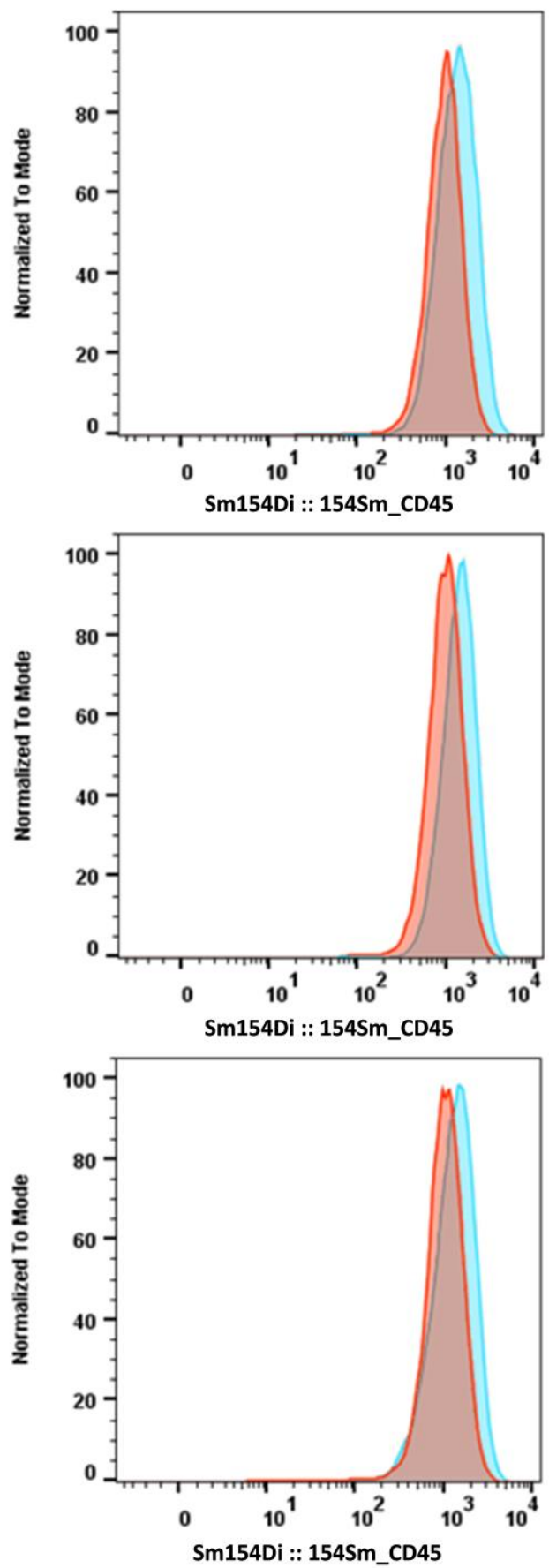

Fig. 15 Overlayed histograms of Jurkat (CD20[-], CD45[+]) (blue) and Ramos (CD20[+], CD45 [+]) (red) cells on ${ }^{115}$ In and ${ }^{154}$ Sm channels at various titers at month 0 .

Titration of the Indium polylysine NAv conjugate at the range of 0.25-1 $\mu \mathrm{g} \cdot \mathrm{mL}^{-1}$ shows expected trend of signal increase on CD20 positive Ramos cells. However, mean ${ }^{115}$ In counts per cell are considerably lower than in the previous experiments with $\mathrm{HL}-60$
In addition, the signal-noise ratio was evaluated to 8 on average by comparison to CD20 negative Jurkat cells. Nevertheless, these experiments also proved the feasibility of detecting multiple markers (CD20[+] by the ${ }^{115}$ In channel and CD45[+] by the ${ }^{154} \mathrm{Sm}$ 


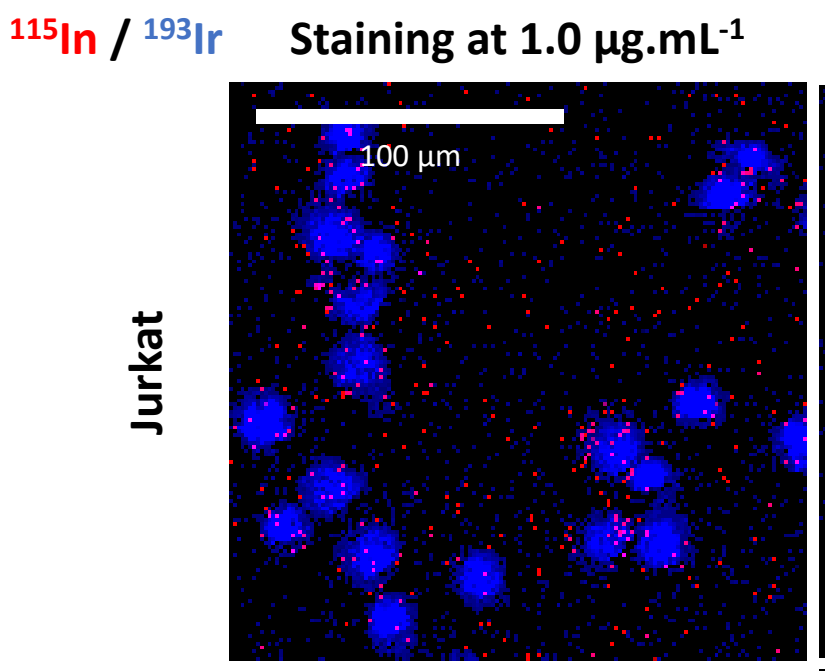

\section{Staining at $2.0 \mu \mathrm{g} \cdot \mathrm{mL}^{-1}$}
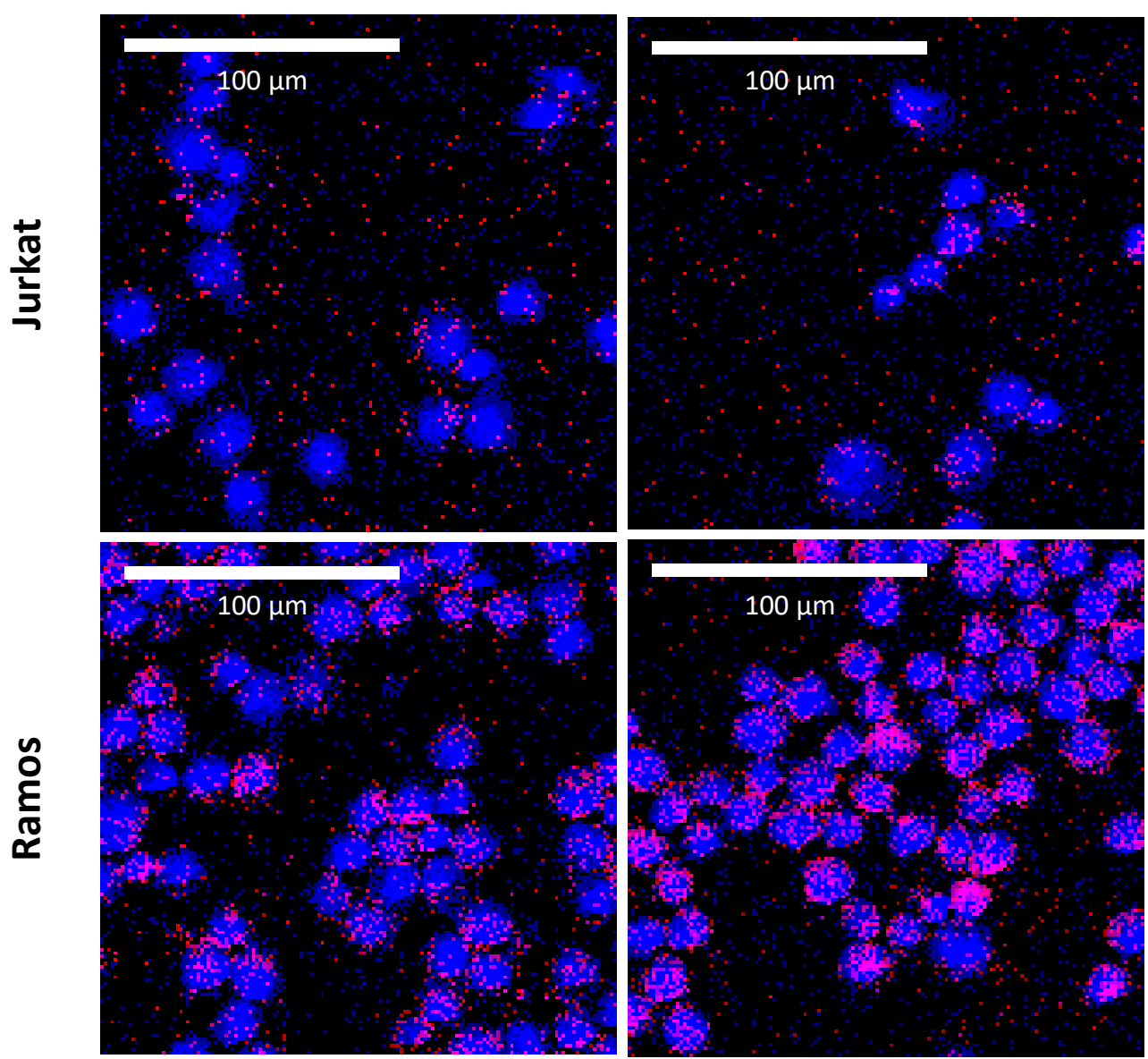

Figure 16. IMC images of Jurkat (CD20[-], CD45[+]) and Ramos (CD20[+], CD45 [+]) cells stained with indium NAv conjugate at various titers at month 0 .

channel) in sequential staining steps. This is very encouraging for the future use of $\operatorname{In}($ III) containing polymers in multiparametric immunoassays. The $1 \mu \mathrm{g} \cdot \mathrm{mL}^{-1}$ titer as well as a higher one $\left(2 \mu \mathrm{g} \cdot \mathrm{mL}^{-1}\right)$ were run under IMC to better visualize cells. Various threshold maximum were used to enhance images' quality (Figure 16).

The commercially available Maxpar ${ }^{\circledR}$ metal labelling kits contain the polymer functionalized by other types of chelators and the isotopically pure metal salt solution so that the chelation occurs just prior to use. This strategy is not possible with the use of cb-te2pa as indium(III) chelator since the metalation requires long reaction time at 80 to $100^{\circ} \mathrm{C}$. So, the polymer must already be charged with the metal before conjugation to the antibody. To evaluate the stability of the bioconjugated In(III)-MCP-NAv, it was stored at $4^{\circ} \mathrm{C}$ for 3 months and used for Ramos and Jurkat labelling in the same way as described just above.

The new histograms plotted after 3 months are presented on Figure S7 in Supporting Material. The ${ }^{115} \mathrm{In}$ and ${ }^{154} \mathrm{Sm}$ counts are reported is Table 4 and Table S2 in Supporting Material respectively. The signal-noise ratio was evaluated to 37 on average by comparison to CD20 negative Jurkat cells. Surprisingly, the signal-noise ratio drastically decreased with the increase of stain concentration.

A bimodal distribution for the $1 \mu \mathrm{g} / \mathrm{mL}$ titer can be observed on Ramos positive cells. This phenomenon could be related to an overloading of the Neutravidin conjugate Indium complex to the surface of the Ramos cells. Crosslinking could generate a codetection of two separate but close cell events, and could not be resolved as a single unimodal Gaussian distribution for the Indium channels. The lowest titers show normal distributions.

In general, the good discrimination of negative and positive populations after 3 months attests about the stability of the indium polymer. It is important to notice that the storage of lanthanideconjugated antibodies can lead to a slight loss of signal. ${ }^{25}$

\section{Conclusion}

The very kinetically inert $[\ln (\mathbf{c b}-\mathrm{te} 2 \mathrm{pa})]^{+}$complex was conjugated on a biotin ending polylysine polymer. The resulting In(III)-metal containing polymer was then conjugated on biotinylated beads thought the very strong non-covalent biotin/neutravidin interaction. Despite a poor loading of In(III) chelates of the polymer, that could be improved by other technics, IMC images of high quality could be obtained based on the ${ }^{115}$ In detection. These positive results encouraged us to study immunostaining experiments involving $\ln ($ III)-MCP. The $\ln ($ III) polylysine was used to label the anti CD20 antibody again using the biotin/neutravidin recognition. The bioconjugate was then used for the detection of the highly expressed CD20 proteins. Ramos (CD2O[+] and HL-60 
(CD20[-]) cell lines were co-stained with the bioconjugate at various titers. After improvement of the staining conditions, both IF-M and CyTof analyses confirmed the specific binding of modified anti-CD20 onto Ramos cells. More precisely, CyTOF histograms constructed on the ${ }^{115}$ In detection highlighted the possibility to define and separate two populations (Ramos expressing CD20 and HL-60 having no CD20 antigens) with a good ratio signal-to-noise. Finally, new functionality tests involving Jurkat cells (CD20[-]) were conducted both to prove the inertness of In(III)-MCP-Nav over a three-month storage period and the possibility of multiplexing experiments involving the ${ }^{115}$ In channel.

More optimization are necessary to increase the number of $\operatorname{In}($ III) chelates per polymer to counter-balance the low ion transmission of In(III), however these first results are very encouraging for the future use of [In(cb-te2pa) $]^{+}$based polymers for mass cytometry.

\section{Experimental part}

A- Synthesis and characterizations of indium chelator containing polymers

\section{Materials}

Reagents, solvents and Millipore Amicon spin filters $(15 \mathrm{~mL}, 3 \mathrm{kDa}$ MWCO) were purchased from Aldrich Chemical Co, unless otherwise noted, and used without further purification. N-1[-2,2'(ethylenedioxy)diethyl-1'-amino]biotinylamide (Biotin-Initiator) $^{26}$ and $\left[\ln \left(\boldsymbol{p}-\mathrm{NH}_{2}-\mathrm{CH}_{2} \mathbf{P h}-\mathrm{cb}-\mathrm{te} 2 \mathrm{pa}\right)\right]^{+},{ }^{19}$ were synthesized as previously described.

Water was purified through a Milli-Q water purification system (18 $\mathrm{m} \Omega \mathrm{cm}$ ). DMF solvent was freshly distilled.

\section{Instrumentation}

The molecular weights and polydispersities of water-soluble polymer samples were measured with a Viscotek size exclusion chromatograph (SEC) equipped with a Viscotek VE3210 UV/VIS detector, VE3580 refractive index detector, and Viscotek ViscoGEL G4000PWXL and G2500PWXL columns (kept at $30^{\circ} \mathrm{C}$ ). The flow rate was maintained at $1.0 \mathrm{~mL} / \mathrm{min}$ using a Viscotek VE1122 Solvent Delivery System and VE7510 GPC Degasser. The eluent used was 0.2 $\mathrm{M} \mathrm{KNO}_{3}, 200 \mathrm{ppm} \mathrm{NaN}$, and the system was calibrated with poly (methacrylic acid) standards. Before analysis, polylysine samples were first treated with an excess of succinic anhydride to convert cationic pendant groups to anionic carboxyl groups. Polylysine (2.1 $\mathrm{mg}$ ) was dissolved in carbonate buffer $(\mathrm{pH} 9.4,0.1 \mathrm{M}, 1 \mathrm{~mL})$. Succinic anhydride $(50 \mathrm{mg})$ was dissolved in DMF $(300 \mathrm{~mL})$. They were then mixed and stirred at room temperature for 1 hour. Afterwards, the polymer solution was washed with DIW by using 3 kDa spin filter. The yielded solution was used directly for GPC analysis.

${ }^{1} \mathrm{H}$ NMR spectra were recorded on a Varian Mercury 400 spectrometer (at the University of Toronto) or on a $500 \mathrm{MHz}$ Bruker spectrometer ("Service commun" of the University of Brest). The NMR samples were prepared in a $3 \mathrm{~mm}$ tube at $10 \mathrm{mg} \cdot \mathrm{mL}^{-1}$ and the spectra were collected as 128 transients with a relaxation delay of 10 seconds. Adjusted molecular weights were calculated by assuming at least $\mathrm{a} \pm 5 \%$ error on ${ }^{1} \mathrm{H}$ NMR integrations when good resolution was achieved. ${ }^{7,27}$

UV/Vis absorption spectra were measured using a Perkin Elmer Lambda 35 UV/Vis spectrometer.

ICP-MS was performed at Fluidigm ${ }^{R}$ and was measured on a PerkinElmer SCIEX Elan 9000 instrument equipped with an autosampler. Samples were prepared by taking $1 \mu \mathrm{L}$ from the studied solution at supposed concentration of $10^{-4} \mathrm{~g} / \mathrm{l} / \mathrm{g}$ of solution and successively diluted with $2 \% \mathrm{HNO}_{3}$ solution until a supposed concentration of 1 $\mathrm{ppb}$. Titers at $1 \mathrm{ppb}$ and $10 \mathrm{ppb}$ were prepared from a commercial solution of Indium standards in $2 \% \mathrm{HNO}_{3}$. Total volume for a sample is $1 \mathrm{~mL}$. Thanks to the titers' indium content, actual indium content in samples was measured and compared with theoretical values. Theoretical values were calculated by assuming all the available functions onto the polymer were reacting with the NCS indium complexes and therefore each position was containing an indium atom. By reporting actual indium content on theoretical indium content, one can determine the number of indium carried by the metal chelating polymer.

FPLC SEC characterizations were acquired on an Akta Pure FPLC instrument equipped with Superose 6 and Superdex 200 Inc columns in the 5-150 GL format, plugged in series. Chromatograms were recorded with UV detection set at $219 \mathrm{~nm}$ and $280 \mathrm{~nm}$ and run in PBS with a $0.15 \mathrm{~mL} . \mathrm{min}^{-1}$ flow rate. Samples to be injected were prepared with the concentration of $0.5 \mu \mathrm{g} / \mu \mathrm{L}$ and $20 \mu \mathrm{l}$ of sample solution is injected for each test.

\section{$\mathrm{N}_{\mathcal{E}}$-Trifluoroacetyl-L-lysine-N-Carboxyanhydride (TFA-L-Lys-NCA).}

TFA-L-Lysine (13.1 g, $54.1 \mathrm{mmoles})$ was mixed with $120 \mathrm{~mL}$ of anhydrous THF in a $500 \mathrm{~mL}$ three-neck flask. To this $15 \% \mathrm{wt}$ phosgene in toluene (75 mL, 105.1 mmoles) was added, the solution became cloudy. The mixture was heated up to $65^{\circ} \mathrm{C}$. After $30 \mathrm{~min}$, the solution became less cloudy and then hazy after $1 \mathrm{~h}$ after complete dissolution of TFA-L-Lysine. After $4 \mathrm{~h}$, the reaction mixture was cooled down to room temperature. Nitrogen was bubbled into the solution to remove unreacted phosgene, and the outlet was immersed in a $\mathrm{NaOH}$ solution to trap and neutralize gaseous phosgene. Anhydrous hexane $(200 \mathrm{~mL})$ was added to the flask that was placed in the freezer overnight to precipitate the product. The product was obtained by vacuum filtration and dried under vacuum to yield $12.5 \mathrm{~g}$ of a white solid (ca. 86\%).

${ }^{1} \mathrm{H}$ NMR (400 MHz, DMSO-d6, $\left.298 \mathrm{~K}\right) . \delta$ (ppm) $9.4(\mathrm{~s}, 1 \mathrm{H}$, amide $\mathrm{NH}), 9.1(\mathrm{~s}, 1 \mathrm{H}$, amide $\mathrm{NH}), 4.4(\mathrm{t}, 1 \mathrm{H}, \mathrm{NC} \underline{\mathrm{H}}-\mathrm{C}=\mathrm{O}), 3.2(\mathrm{t}, 2 \mathrm{H}$, $\left.\mathrm{CH}_{2} \mathrm{~N}\right), 1.2-1.8\left(\mathrm{~m}, 6 \mathrm{H},\left(\mathrm{CH}_{2}\right)_{3}\right)$

Poly(N $\varepsilon$-Trifluoroacetyl-L-lysine)-biotin (Poly(TFA-L-Lys)-Btn).

In a $30 \mathrm{~mL}$ glass vial, TFA-L-Lys-NCA monomer $(1.0 \mathrm{~g})$ was dissolved in anhydrous DMF (10 mL). Subsequently, Biotin-Initiator (28.71 $\mathrm{mg}$ ) was added to the dissolved monomer solution. The reaction was carried out for 8 hours at $0^{\circ} \mathrm{C}$ using an ice bath. After 8 hours, the polymer was precipitated by pouring the solution into diethyl ether $(100 \mathrm{~mL})$. The polymer was then sedimented at $2700 \mathrm{~g}$ for 10 min. The polymer was then dissolved in methanol and reprecipitated in diethyl ether. This process was repeated 4 times to remove DMF from the polymer sample. The precipitated polymer was dried under vacuum overnight and stored at $-20{ }^{\circ} \mathrm{C}$ for further use. $D_{n}{ }^{N M R}=52 ; M_{n}{ }^{N M R}(g / m o l)=12000$. 
Poly(L-lysine)-biotin (Poly(L-Lys)-Btn).

Poly(TFA-L-Lys)-Btn (400 mg) was dissolved in methanol $(47.5 \mathrm{~mL})$. To this, $\mathrm{K}_{2} \mathrm{CO}_{3}$ (500 mg in $2.5 \mathrm{~mL}$ water) was added. The solution turned cloudy, but upon heating with a water bath at $65^{\circ} \mathrm{C}$ for 30 min, the solution turned clear. The mixture was stirred overnight at room temperature and then the solvent was removed with a rotary evaporator. After evaporation of the solvent, water (ca. $20 \mathrm{~mL}$ ) was added to dissolve the deprotected polymer. The $\mathrm{pH}$ of the solution was brought down to 6 using glacial acetic acid. At this point, the polymer solution was poured into a $15 \mathrm{~mL} 3000$ MWCO spin filter and washed 5 times using water. Acetic acid was added to the polymer solution to avoid damaging the spin filter, as the $\mathrm{K}_{2} \mathrm{CO}_{3}$ made the solution very basic $(\mathrm{pH} \sim 12)$. The concentrated polymer solution was then freeze dried and stored at $-20{ }^{\circ} \mathrm{C}$ for further use. $\mathrm{M}_{\mathrm{n}}^{\mathrm{SEC}}(\mathrm{g} / \mathrm{mol})=13400 ; \mathrm{DP}_{\mathrm{n}}{ }^{\mathrm{NMR}}=52 ; \mathrm{PDI}(\Theta)=1.04$

\section{PEGylation of biotin-poly-L-lysine.}

The deprotected poly-L-lysine Poly(L-Lys)-Btn $(20.8 \mathrm{mg}, \mathrm{MW}=$ 13400 g.mol ${ }^{-1}, 1.55 \mu \mathrm{mol}$ ) was dissolved in $200 \mu \mathrm{L}$ of carbonate buffer (0.1 M, pH = 9.1). Methyl-PEG8-NHS (18.8 mg, 25 eq.) was dissolved in $200 \mu \mathrm{L}$ of freshly distilled DMF then added to the first solution. The mixture was stirred at room temperature for $5 \mathrm{~h}$. The solution was diluted to have $\mathrm{DMF} \leq 5 \%$ and was introduced into a $15 \mathrm{~mL} 3000$ MWCO spin filter. Dilution is mandatory to avoid damaging the spin filter. After removing DMF, the concentrated polymer solution was washed 4 times with deionized water $(4000 \mathrm{~g}$, $30 \mathrm{~min}$ ) and freeze-dried to afford the desired compound as a white powder (21.4 mg, 93\%).

${ }^{1} \mathrm{H}$ NMR (500 MHz, $\left.\mathrm{D}_{2} \mathrm{O}, 298 \mathrm{~K}\right) . \delta(\mathrm{ppm})[4.62(\mathrm{~m}, 1 \mathrm{H}), 4.43(\mathrm{~m}, 1 \mathrm{H})]$ (NH-CH Btn), 4.30 (br s, 52H, NH-CH-CO pLys), $3.87-3.51$ (m, 529H, $\left.\mathrm{O}-\mathrm{CH}_{2}-\mathrm{CH}_{2}-\mathrm{O}\right), 3.39$ (s, 52H, $\left.\mathrm{CH}_{3}-\mathrm{O}\right)$, [3.18 (br s), 2.97 (br s)] $(102 \mathrm{H}$, CO-NH-CH 2 pLys), 2.80 (d, 2H, S- $\mathrm{CH}_{2}$ Btn), 2.53 (br s, 35H, NH-CO$\mathrm{CH}_{2}$ PEG), 2.28 (t, 2H, NH-CO-CH $\mathrm{CH}_{2}$ ), 1.92 (s, 58H, $\mathrm{CH}_{3}$ Ac.), $1.87-$ 1.25 (br m, 314H, $\mathrm{CH}_{2}-\mathrm{CH}_{2}-\mathrm{CH}_{2}$ Lys). $\mathrm{M}_{\mathrm{n}}^{\mathrm{NMR}}(\mathrm{g} / \mathrm{mol})=14900$; $D P_{n}{ }^{N M R}=52$.

\section{Attachment of [ $\left.\ln \left(\mathrm{p}-\mathrm{NH}_{2}-\mathrm{CH}_{2} \mathrm{Ph}-\mathrm{cb}-\mathrm{te} 2 \mathrm{pa}\right)\right]^{+}$to PEG-p-Lys-Btn.}

The protocol was adapted from ref19. $\mathrm{NaHCO}_{3}$ was weighed out (47 $\mathrm{mg}, 15 \mathrm{eq}$ ) in a $10 \mathrm{~mL}$ sealed tube. After adding $500 \mu \mathrm{L}$ of $\mathrm{CHCl}_{3}, 30$ $\mu \mathrm{L}$ of thiophosgene (10 eq) was introduced into the tube. $28 \mathrm{mg}$ ( $\mathrm{n}$ $\left.=3.7710^{-2} \mathrm{mmol}\right)$ of $\left[\mathrm{In}\left(\boldsymbol{p}-\mathbf{N H}_{2}-\mathbf{C H}_{2} \mathbf{P h} \text {-cb-te2 } \mathbf{p a}\right)\right]^{+}$dissolved in 200 $\mu \mathrm{L}$ of deionized water was poured into the tube and the solution was completed with $400 \mu \mathrm{L}$ of deionized water. The two-phase mixture was strongly stirred at room temperature for $2 \mathrm{~h} 15$. The organic layer, containing the thiophosgene, was carefully removed from the tube; the aqueous layer was washed 5 times with $1 \mathrm{~mL}$ of $\mathrm{CHCl}_{3}$ then filtered and directly injected into the next step.

[ $\mathrm{In}\left(\boldsymbol{p}\right.$-NCS- $\mathrm{CH}_{2} \mathrm{Ph}$-cb-te2pa) $] \mathrm{HCO}_{3}\left(\mathrm{n}=3.7710^{-2} \mathrm{mmol}, 2.6\right.$ eq per free $-\mathrm{NH}_{2}$ position) and carbonate-containing solution was completed with $1.7 \mathrm{~mL}$ of deionized water. PEG-poly(L-Lys)-Btn (6.1 $\mathrm{mg}, \mathrm{MW}=14900 \mathrm{~g} \cdot \mathrm{mol}^{-1}, 0.41 \mu \mathrm{mol}$ ) was dissolved in $3.3 \mathrm{~mL}$ of freshly distilled DMF and introduced into the first solution. The mixture was stirred at room temperature overnight. The solution was diluted to have DMF $\leq 5 \%$ and was introduced into a $15 \mathrm{~mL}$ 3000 MWCO spin filter. After removing DMF, the concentrated polymer solution was washed 3 times with deionized water $(4000 \mathrm{~g}$
$30 \mathrm{~min}$ ) and freeze-dried to afford the desired compound as a yellowish powder (4.2 mg, $\left.\mathrm{MW}_{\mathrm{Th}}{ }^{*}=42000 \mathrm{~g} \cdot \mathrm{mol}^{-1}, 24 \%\right)$.

*Theoretical $\mathrm{M}_{\mathrm{n}}$ was calculated by assuming all available amines are carrying an indium complex, that $\mathrm{DP}_{\mathrm{n}}$ is close to the one obtained in previous steps and that the counteranion is $\mathrm{HCO}_{3}{ }^{-}$.

${ }^{1} \mathrm{H}$ NMR $\left(500 \mathrm{MHz}, \mathrm{D}_{2} \mathrm{O}, 298 \mathrm{~K}\right), \delta[8.24-8.02(\mathrm{br} \mathrm{m}), 7.95(\mathrm{~s}), 7.85-$ 7.50 (br m)] ( $\mathrm{CH}_{A r}$ Pico), [7.42 - 7.14 (br m), $7.14-6.78$ (br m), 6.45 - 6.22 (br m)] ( $\mathrm{CH}_{\mathrm{Ar}}$ PhNHSNH), $5.38-4.95$ (br m, $\mathrm{CH}_{2}$ Pico), $4.29-$ 3.86 (br m, $\mathrm{CH}_{2}-\alpha-\mathrm{N}, \mathrm{NH}-\mathrm{CH}-\mathrm{CO}$ pLys), $3.85-3.41$ (br m, $\mathrm{CH}_{2}-\alpha-\mathrm{N}, \mathrm{O}-$ $\mathrm{CH}_{2}-\mathrm{CH}_{2}-\mathrm{O}$ ), 3.37 (br s, $\mathrm{CH}_{2}-\alpha-\mathrm{N}, \mathrm{CH}_{3}-\mathrm{O}$ ), $3.25-2.29$ (br m), $2.18-$ 1.16 (br m, $\mathrm{CH}_{2}-\beta-\mathrm{N}, \mathrm{CH}_{2}-\mathrm{CH}_{2}-\mathrm{CH}_{2}$ pLys)

Biotin peaks are not observed to set a reference, therefore peak integration is not available. $\mathrm{M}_{\mathrm{n}}{ }^{\mathrm{Th}}(\mathrm{g} / \mathrm{mol})=42000 ; \mathrm{DP}_{\mathrm{n}}{ }^{\mathrm{NMR}}=52$.

\section{B - Conjugation to FITC-NAv and incubation on biotinylated beads.} Materials.

Biotin-coated microspheres $(9.78 \mu \mathrm{m}, 5.9 \mathrm{nmol}$ of biotin $/ \mathrm{mg})$ were purchased from Bangs Laboratories Inc. (CP 10000 )

\section{Instrumentation}

Protein quantification of all the FITC-NAv conjugates and derivatives were performed on a UV-Vis NanoDrop ${ }^{\mathrm{TM}} 2000$ spectrophotometer. $2 \mu \mathrm{L}$ of sample were placed on the NanoDrop instrument and absorption was read at specific wavelength (280 nm or $495 \mathrm{~nm}$ ). Blank sample was realized with PBS. Bradford protein quantification was realized with the Pierce ${ }^{\mathrm{TM}}$ Coomassie Protein assay kit (Cat. \#23200) and was run with a specific program of the NanoDrop instrument. The instrument used for Imaging Mass Cytometry is commercially called Hyperion ${ }^{\mathrm{TM}}$ Imaging System.

IF-M measurements were carried out on an Axio Imager M2 fluorescence microscope (Zeiss) equipped with an AxioCam CCD camera and an AxioCam 506 mono camera.

\section{Modification of Neutravidin (NAv) with Fluorescein-isothiocyanate (FITC).}

$5 \mathrm{mg}$ of neutravidin $(60 \mathrm{kDa}$ ) are dissolved in carbonate buffer (100 $\mathrm{mM}, \mathrm{pH}$ 9.1) to reach a concentration of $2 \mathrm{mg} \cdot \mathrm{mL}^{-1} .40 .8 \mu \mathrm{L}$ of Fluorescein isothiocyanate (FITC) in solution in DMSO (10 mg. $\mathrm{mL}^{-1}$ ) was introduced to the first solution. The mixture was stirred at room temperature for $1 \mathrm{~h} 30$, then poured into a $5 \mathrm{~mL} 3000 \mathrm{MWCO}$ spin-filter and washed 5 times with PBS solution (3 500g, $30 \mathrm{~min}$ ). The sample was concentrated to $500 \mu \mathrm{L}$ prior to purification by FPLC. Fractions containing the purified FITC-NAv were collected and concentrated to $500 \mu \mathrm{L}$ (3 $000 \mathrm{MWCO}, 3500 \mathrm{~g}$ ).

NAv concentration and FITC/NAv molar ratio were evaluated by UVVis NanoDrop spectrometer following Sigma procedure from the FITC product information. Results led to a $2.6 \mathrm{mg} \cdot \mathrm{mL}^{-1} \mathrm{NAv}$ solution with $3.3 \mathrm{~mol}$ of FITC per mol of NAv.

\section{Conjugation of In(cb-te2pa)-PEG-p-Lys-Btn to FITC-NAv}

To a solution of FITC-NAv $\left(60 \mu \mathrm{g}\right.$ at $\left.2.6 \mathrm{mg} \cdot \mathrm{mL}^{-1}\right)$ was added $1.3 \mathrm{eq}$. of In(cb-te2pa)-PEG-p-Lys-Btn (55.6 $\mu \mathrm{g}$, in solution at $1 \mathrm{mg} \cdot \mathrm{mL}^{-1}$ in deionized water). The addition was done in 2 times: first half ( 27.8 $\mu \mathrm{L})$ was introduced and pipette-mixed into the FITC-NAv solution and left for $1 \mathrm{~h}$ at r.t, protected from light. Then, the second half was introduced and left for $1 \mathrm{~h}$ in the same conditions. The resulting indium conjugate was washed 4 times with $400 \mu \mathrm{L}$ of PBS using a 
$0.5 \mathrm{~mL} 100 \mathrm{kDa}$ MWCO spin-filter (12 $000 \mathrm{rcf}, 10 \mathrm{~min}$ ). Recovery yield was determined by reading FITC absorbance at $495 \mathrm{~nm}$ on a UV-Vis NanoDrop spectrometer; around $10-12 \mu \mathrm{g}$ were recovered and then stored in the fridge at $0.5 \mathrm{mg} \cdot \mathrm{mL}^{-1}$ for further tests on cells and beads.

The same protocol can be applied with a solution of In(cb-te2pa)PEG-p-Lys-Btn at $2 \mathrm{mg} . \mathrm{mL}^{-1}(55.6 \mu \mathrm{g}$, i.e. $2 \times 13.9 \mu \mathrm{L})$

Incubation of the indium FITC-NAv conjugate on biotinylated beads.

$10 \mu \mathrm{L}$ of In(cb-te2pa)-PEG-p-Lys-Btn-FITC-NAv conjugate (either 0.3 or $0.5 \mathrm{mg} \cdot \mathrm{mL}^{-1}$ solution) was introduced in a $1.5 \mathrm{~mL}$ Eppendorf tube, then $5 \mu \mathrm{L}$ of biotin-coated microspheres $(0.78 \mu \mathrm{m}, 5.9 \mathrm{nmol}$ of biotin per $\mathrm{mg}$ ) was added to the solution. The tube was stirred vigorously overnight at room temperature while being protected from light. The beads solution was centrifugated at $5000 \mathrm{~g}$ for 5 min and supernatant removed from the tube. The beads solution was washed 3 times with $30 \mu \mathrm{L}$ of PBS following the same procedure. Beads were finally stored in the fridge in $20 \mu \mathrm{L}$ of PBS.

\section{IF-M slide preparation}

$3 \mu \mathrm{L}$ of indium bead solution were deposited on a glass microscope slide with cavity wells. Sample was diluted with $100 \mu \mathrm{L}$ of PBS prior to covering with a cover-slip. Slides were protected from light and run under the immunofluorescence microscope within the hour following preparation. Beads from commercial solution were used for blank images.

\section{IMC slide preparation}

$2 \mu \mathrm{L}$ of indium bead solution were deposited on a glass slide for IMC. Once dry, the slide was placed on a hot plate and beads were melted at $200^{\circ} \mathrm{C}$ for $10 \mathrm{~min}$.

After 1-month storage in the fridge, the indium beads were centrifugated anew $(5000 \mathrm{~g}, 5 \mathrm{~min}$ ) and washed 3 times with $30 \mu \mathrm{L}$ of PBS. They were finally resuspended in $20 \mu \mathrm{L}$ of PBS. A glass slide for IMC was prepared again.

\section{C - Functionality tests on cells}

\section{Materials}

CD20 (2H7) biotinylated antibody and Human TruStain FcX Fc Block were obtained from BioLegend. Ramos, $\mathrm{HL}-60$ and Jurkat cells were obtained from ATCC ${ }^{103} \mathrm{Rh},{ }^{191} \mathrm{Ir}$ and ${ }^{193} \mathrm{Ir}$ intercalators were obtained from Fluidigm. Cells were fixed with 1.6\% PFA prepared by dilution ùfrom a Thermo Scientific commercial 16\% PFA solution in PBS.

\section{General procedure}

Staining. Dead cells were stained with ${ }^{103} \mathrm{Rh}$ intercalator, diluted by 500 from stock solution, at $37^{\circ} \mathrm{C}$ for $15 \mathrm{~min}$ with $5 \%$ of $\mathrm{CO}_{2}$. Primary and secondary stains were performed on ice at $4{ }^{\circ} \mathrm{C}$ during $1 \mathrm{~h}$ without BSA in cold PBS. Primary staining was done in $100 \mu \mathrm{L}$ final volume of primary antibody solution at $5 \mu \mathrm{g} \cdot \mathrm{mL}^{-1}$ per each cell pellet of $2 \times 10^{6}$ cells. Indium FITC-NAv conjugate titers were prepared with cold PBS from the stock solution previously centrifuged at full speed for $5 \mathrm{~min}$ to spin down aggregates.
Incubations with indium FITC-NAv conjugates were resuspended in $100 \mu \mathrm{L}$ of conjugate solution per cell pellet. Cells were then fixed overnight at $4^{\circ} \mathrm{C}$ with $400 \mu \mathrm{L}$ of fresh $1.6 \%$ PFA solution in PBS. 50 $\mu \mathrm{L}$ were taken away for ImmunoFluorescence Microscopy (IF-M). Prior to analysis, cells were counterstained for cell identification on CyTOF with DNA Ir-intercalator. Cell pellets were incubated with $400 \mu \mathrm{L}$ of $\mathrm{a}{ }^{191} \mathrm{Ir}$ and ${ }^{193} \mathrm{Ir}$ intercalator solution (at a final concentration of $125 \mathrm{nM}$ ), at room temperature for $30 \mathrm{~min}$.

Acquisition on CyTOF. Cell pellets were resuspended in EQ4 bead solution, diluted 1:10 with Maxpar ${ }^{\circledR}$ Cell Acquisition Solution, and filtered through a $35 \mu \mathrm{M}$ cell strainer. Samples were resuspended to a concentration such that 200 events/s were collected. Acquisition was stopped after recording 100000 events.

ImmunoFluorescence Microscopy. Samples were stained with DAPI $(0.5 \mu \mathrm{g} / \mathrm{mL})$ at room temperature for $20 \mathrm{~min}$, while being protected from light, for cell nuclei identification. After washing, slides were prepared by using Superfrost+ slides with $10 \mu \mathrm{L}$ of cell solution (approximately 50000 cells).

Imaging mass cytometry. Slides' samples were prepared by taking $20 \mu \mathrm{L}$ of cells in $0.1 \mathrm{X}$ EQ4 bead solution to be diluted with $100 \mu \mathrm{L}$ of PBS. $100 \mu \mathrm{L}$ of resulting cell solution were deposited on Cell TAK slides and left to adhere for $1 \mathrm{~h}$. Corning ${ }^{\mathrm{TM}}$ Cell-Take slides were prepared according to manufacturer's protocol.

Overtime stability study. Neutravidin was purchased from ThermoFisher as lyophilized powder. It was first purified with FPLC to remove protein aggregates. And then concentrated with spinfilter to $0.83 \mathrm{mg} \cdot \mathrm{mL}^{-1}$ in PBS. In(cb-te2pa)-PEG-p-Lys-Btn solution (64 $\mu \mathrm{L}$ at $2 \mathrm{mg} \cdot \mathrm{mL}^{-1}$ in deionized water) was prepared. $32 \mu \mathrm{L}$ of this solution was first added into NAv solution $(144.6 \mu \mathrm{L})$ and incubated at room temperature for 1 hour. Following that the rest half of the polymer solution was then combined into this Nav solution and incubated with shaking for another 1 hour. Excess free NAv was removed by washing the conjugate solution with $100 \mathrm{kDa}$ spin-filter for 3 times $(12000 \mathrm{~g}, 10 \mathrm{~min})$. Concentration of the NAv was then checked with Bradford assay (4.13 mg. $\mathrm{mL}^{-1}$ in PBS). Cell staining procedure was adapted from the one described above. After ${ }^{103} \mathrm{Rh}$ staining and sterile PBS washing, each tube of cells were resuspended in $180 \mu \mathrm{L}$ of PBS, followed by the addition of $20 \mu \mathrm{L}$ of Fc Block 1:10 diluted in cold PBS for $10 \mathrm{~min}$ at room temperature. Primary staining and incubation of indium-NAv conjugate were performed as before. Cells were then stained with CD45-Sm154 at 1:100 dilution in cold PBS- $0.5 \% \mathrm{BSA}$ at $4^{\circ} \mathrm{C}$ for $30 \mathrm{~min}$. Finally, cells were fixed in fresh $1.6 \%$ PFA in PBS $(400 \mu \mathrm{L}$ per tube) and stored at $4^{\circ} \mathrm{C}$ overnight. Prior to be counted on CyTOF, cells were stained with DNA Ir-Intercalator 1:2000 diluted in PBS for $30 \mathrm{~min}$ at room temperature. For each sample to run, the cells were diluted at a final concentration of 500000 cells/ $\mathrm{mL}$ in $500 \mu \mathrm{L}$ of EQ 4 elements beads diluted 1:10.

\section{Conflicts of interest}

The authors declare that there are no conflicts to declare. 


\section{Acknowledgements}

R.T. and M.B. acknowledge the Ministère de I'Enseignement Supérieur et de la Recherche, the Centre National de la Recherche Scientifique and they thank the "Région Bretagne" and Fluidigm for the ARED and industrial fellowships respectively for L.G. thesis. R.T., M.B. and L.G. also thank the "Service Commun" of NMR facilities of the University of Brest, Bleuenn Gueguen from "Pôle spectrométrie Océan" at the IUEM of Brest for additional ICP-MS analysis and the LBAI Laboratory from University of Brest for giving access to the Flowjo software.

T.C., A.B., N.Z., P.L., O.O. and V.B. are employees of, and receive remuneration from, Fluidigm Corporation. Fluidigm, CyTOF, EQ, Helios, Hyperion, Imaging Mass Cytometry, IMC, Maxpar and MCD are trademarks and/or registered trademarks of Fluidigm Corporation in the United States and/or other countries. All other trademarks are the sole property of their respective owners. Authors thank Stephen Li for his help in reading and providing precious suggestions to improve the quality of the paper.

\section{Notes and references}

For research use only. Not for use in diagnostic procedures.

1. S. C. Bendall, G. P. Nolan, , M. Roederer and P. K. Chattopadhyay, Trends Immunol., 2012, 33, 323-332.

2. B. Bengsch, T. Ohtani, R. Sedaghat Herati, N. Bovenschen, K.-M Chang and E. J. Wherry, J. Immunol. Methods, 2018, 453, 3-10.3. K. R. Atkuri, J. C. Stevens and H. Neubert, Drug Metab. Dispos., 2015, 43, 227-233

4. G.P. Nolan, W. J. Fantl, G. Han, S. C. Bendall and M. H. Spitzer, Nat. Protoc., 2018, 13, 2121-2148.

5. F. J. Hartmann, E. F Simonds and S. C. Bendall, Sci. Rep.,2018, 8, $1-10$.

6. X. Lou, G. Zhang, I. Herrera, R. Kinach, O. Ornatsky, V. Baranov, M. Nitz and M. A. Winnik, Angew. Chem. Int. Ed., 2007, 46, 61116114.

7. P. Liu, A. J. Boyle, Y. Lu, R. M. Reilly and M. A. Winnik, Biomacromolecules, 2012, 13, 2831-2842.

8. S. Erdogan, A. Roby and V. P. Torchilin, Mol. Pharm., 2006, 3, 525530.

9. S. Erdogan, A. Roby, R. Sawant, J. Hurley and V. P. Torchilin, J. Liposome Res., 2006, 16, 45-55.

10. Z. B. Bjornson, G. P. Nolan and W. J. Fantl, Curr. Opin. Immunol., 2013, 25, 484-494.

11. N. M. Green, Adv. Protein Chem., 1975, 29, 85-133.

12. N. M. Green, Biochem. J., 1963, 89, 585-591.

13. M. Wojciechowski, R. Sundseth, M. Moreno and R. Henkens, Clin. Chem., 1999, 45, 1690-1693.

14. C. Secchi, P. A. Biondi, A. Berrini, T. Simonic and S. Ronchi, J. Immunol. Methods, 1988, 110, 123-128.

15. Y. Takata, T. Moriyama, Y. Fukumori, A. Yoden, M. Shima and S. Inai, J. Immunol. Methods, 1989, 117, 107-113.

16. M. J. Champagne, R. Higgins, J. M. Fairbrother and D. Dubreuil, Can. J. Vet. Res., 1991, 55, 239-245.

17. Y. Lu, G. Ngo, N. Mbong, P. Liu, C. Chan, Z. Cai, D. Weinrich, A. J. Boyle, R. M. Reilly and M. A. Winnik, Biomacromolecules, 2014, 15, 2027-2037.

18. Y. Lu, M. Chau, A. J. Boyle, P. Liu, A. Niehoff, D. Weinrich, R. M. Reilly and M. A. Winnik, Biomacromolecules, 2012, 13, 1296-1306.

19. L. Grenier, M. Beyler, C. Platas-Iglesias, T. Closson, D. Esteban Gómez, D. S. Seferos, P. Liu, O. I. Ornatsky, V. Baranov and R.
Tripier, Chem. Eur. J., 2019, 25, 15387-15400.

20. L. Tong, E. Lu, J. Pichaandi, G. Zhao and M. A. Winnik, J. Phys. Chem. C, 2016, 120, 6269-6280.

21. M. D. Leipold, G. Obermoser, C. Fenwick, K. Kleinstuber, N. Rashidi, J. P. McNevin, A. N. Nau, L. E. Wagar, V. Rozot, M. M. Davis, S. DeRosa, G. Pantaleo, T. J. Scriba, B. D. Walker, L. R. Olsen and H. T. Maecker, J. Immunol. Methods, 2018, 453, 37-43.

22. W. R. Zipfel, R. M. Williams, R. Christie, A. Y. Nikitin, B. T. Hyman and W. W. Webb, Proc. Natl. Acad. Sci. USA, 2003, 100, 7075-7080.

23. J. R. Lakowicz, Principles of Fluorescence Spectroscopy, Springer Ed., 2006.

24. Y. Zhang, X. Chen, C. Gueydan and J. Han, Cell Research, 2018, 28, 9-21.

25. H. R. Sumatoh, K. W. W. Teng, Y. Cheng and E. W. Newell, Cytom. Part A, 2017, 91, 48-61.

26. P. Liu, Z. Cai, J. Kang, A. Boyle, J. Adams, Y. Lu, G. Mbong, S. Sidhu, R. Reilly and M. Winnik, Biomacromolecules, 2014, 15, 715725.

27. D. Majonis, I. Herrera, O. Ornatsky, M. Schulze, X. Lou, M. Soleimani, M. Nitz and M. A. Winnik, Anal. Chem., 2010, 82, 89618969. 


\section{Graphical Abstract}

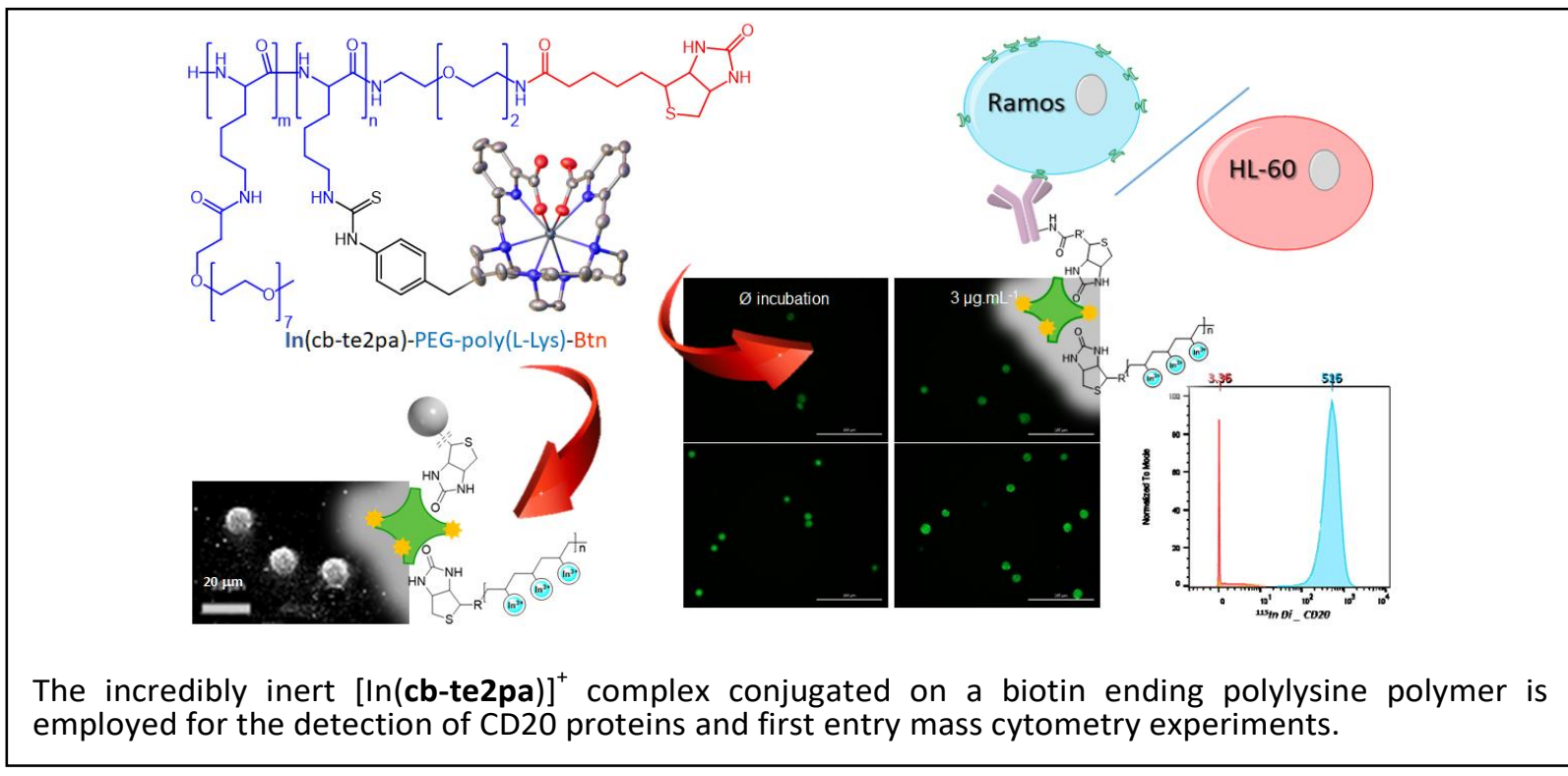

